\title{
CAMPAÑAS ELECTORALES Y PUBLICIDAD POLÍTICA EN EL REINO UNIDO
}

\author{
José Rúas Araujo ${ }^{1}$ \\ Universidad de Vigo \\ joseruas@uvigo.es
}

Material original autorizado para su primera publicación en la revista académica REDMARKA. Revista Digital de Marketing Aplicado

https://doi.org/10.17979/redma.2012.01.08.4730

Recibido: 15 Abril 2012

Aceptado: 24 Mayo 2012

\section{Resumen}

Tras una contextualización del papel de los medios y la observación de la acusada influencia de los actores políticos y mediáticos en medio de la creciente profesionalización de la comunicación política, este artículo muestra las campañas electorales llevadas a cabo en el Reino Unido durante las cuatro últimas legislaturas, tres bajo el gobierno laborista $(1997,2001$ y 2005) y la última, ganada por los conservadores (2010).

Un repaso por los cambios y evolución experimentados en dos décadas a través del análisis descriptivo de las estrategias de comunicación y la publicidad electoral de laboristas, tories y liberal-demócratas, cuya creatividad se alimentó sobre la discusión de la progresiva americanización de las campañas, centradas en la negatividad y personalización de a imagen los líderes.

Palabras clave: Campañas Electorales, Publicidad Política, Reino Unido

\footnotetext{
${ }^{1}$ José Rúas Araújo es profesor titular de comunicación electoral e institucional de la Facultad de Ciencias Sociales y de la Comunicación de la Universidad de Vigo, autor del Manual del Candidato Electoral (Madrid: Catarata, 2011) y asesor de comunicación y formación de candidatos y partidos.
} 


\section{Abstract}

ELECTORAL CAMPAIGNS AND POLITICAL ADVERTISEMENT IN THE UNITED KINGDOM

After a contextualization of the role of the media and observation of the marked influence of political actors and media in the middle of the growing professionalization of political communication, this article shows the electoral campaigns carried out in the United Kingdom during the last four legislatures, three under the Labour Government (1997, 2001 and 2005) and the last won by the conservatives (2010).

A review by experienced over two decades through the descriptive analysis of the strategies of communication and electoral advertising of labour, tories and liberal-democrats changes and evolution whose creativity is fueled on the discussion of the progressive Americanization of campaigns, focused on negativity and the customization on the image the leaders.

Key Words: Electoral Campaigns, Political Advertisement, Britain. 


\section{El contexto de la mediatización política}

El papel de la gestión de las noticias y los medios en la política británica puede ser visto como una anomalía o como una consecuencia básica de la mediatización de la política, justificada en parte por la influencia de los spin doctors y un modelo de periodismo muy propio de los países anglosajones, que lleva al extremo los incentivos económicos y la influencia de los actores políticos a la hora de dar forma a las noticias (Brants y Voltmer, 2011, p.62).

Tradicionalmente, en el Reino Unido se ha observado el papel de los actores políticos, que pueden influir en las noticias facilitando determinado tipo de información y negando el acceso a otra (Gandy, 1982). Una influencia cuyo origen se ha buscado en el bajo interés e identificación de los ciudadanos con la política, la consideración de la prensa británica como altamente partidista (Hallin y Mancini, 2004, p.210) y unas reglas de juego que crean oportunidades para influir en el contenido de los medios y viceversa ${ }^{1}$.

Así, se acepta que los políticos y sus asesores presenten la información de forma parcial y engañosa y los periodistas sean poco selectivos (Ingham, 2003, p.68), ante las presiones ejercidas por los spin doctors, que despliegan una particular noción de equidad para tratar de limitar la forma en que operan los periodistas.

Los medios de comunicación han construido una "jerarquía gradual de acceso" a la información (Waine y Murray, 2009) acorde con las élites políticas, que excluye las voces públicas o alternativas y facilita el dominio del primer ministro sobre el gabinete, de éste sobre los parlamentarios y del partido gobernante sobre la oposición, atendiendo únicamente a la actividad de Westminster y a la recta final de la carrera de caballos (race horse) electoral.

Todo ello produce una situación de una gran competitividad entre los medios, influidos por un sistema político donde las referencias partidistas resultan muy semejantes (dos formaciones históricas, con entrada más reciente de una tercera) y muestran una tendencia a difuminar sus diferencias para situarse en 
el centro político (Downs, 1957, p.243), lo cual se traduce en vagas promesas y ataque directos a la otra parte.

Una creciente "americanización" de la política inglesa (Blumler y Gurevitch, 2001 y Scammell, 1995, p.291), con una fuerte dependencia de las campañas de ataque y un progresivo incremento de la publicidad negativa, en más del $60 \%$ de los spots electorales de conservadores, laboristas y liberal-demócratas, observado ya en los comicios de 1997. Todo ello, aparte de una creciente profesionalización de la comunicación política, centrada cada vez más en la imagen del líder y la cobertura de aspectos relacionados con su personalidad, dimensión privada y cualidades humanas (Langer, 2010, p.60).

Algunos autores describen este nuevo escenario como la llegada de la "tercera etapa del periodismo político" (Esser et al. 2001, p.17), centrada no sólo en las noticias e intrigas políticas, sino también en el papel de la comunicación política como tal, sus campañas, estrategias y tácticas de adaptación a los medios de comunicación como una institución política más.

Y a la cada vez mayor similitud entre las técnicas de investigación y comunicación empleadas entre las campañas entre USA y el Reino Unido (Kavanagh, 1995, p.226), se suman las analogías entre los equipos y personalidades de Tony Blair y Bill Clinton, tanto por edad, como por profesión y los problemas que tuvieron que afrontar para tratar de cambiar la imagen de sus partidos y redefinir el espacio ideológico de centro-izquierda en la búsqueda de una "tercera vía".

De hecho, estrategas del "New Labour" como Philip Gould viajaron a los Estados Unidos para observar y asesorar a la campaña de Clinton en 1992 y consultores de los demócratas americanos, como Paul Begala y James Carville, hicieron contribuciones a la campaña de Blair (Foley, 2000, p.6), aparte los contactos mutuos a través de asociaciones y Think-Tanks progresistas como la Red de Política Progresista o el Instituto para los Valores Familiares. 
Estilos y liderazgos, ambos, en un contexto de disminución de la fe en los partidos y dirigidos a las edades de la televisión y la búsqueda de titulares y frases con gancho, los soundbites del día a los que aludió John Major para criticar el hecho de que Blair apenas le hiciese preguntas de "serio interés" (Gould, 1998, p.295) en el Parlamento.

Por otro lado, está la propia estructura del mercado de medios de comunicación, que exige encontrar "una buena historia" para atraer la audiencia, "empujando cualquier información embarazosa a publicarse ante el temor de que un competidor reciba la historia y obtenga una ventaja comercial" (Campbell, 2007, p.225), aparte de la voluntad de los dueños y editores de los medios para cambiar o moderar su lealtad a uno u otro partido. Así ocurrió con los periódicos controlados por Rupert Murdoch, que pasaron de apoyar a los conservadores a los laboristas, antes de las elecciones de 1997, y de nuevo a los conservadores en 2009, o el caso del Daily Express, de incondicionalmente pro-conservador a Laborista ${ }^{2}$. Casos como el Sun o el Daily Mirror, este último el más fiel, históricamente, a los laboristas, también cambiaron sus posiciones, sobre todo a raíz del apoyo de Blair a la guerra de Irak.

El choque entre políticos y medios ante el incesante goteo de noticias sobre las "mentiras del poder" (Prince, 2010) se mostró durante las últimas décadas, a través de la ruptura del "off the record" y la publicación de múltiples grabaciones ocultas de conversaciones, que alcanzaron su momento álgido recientemente, con el caso de los pinchazos telefónicos a políticos y famosos, con la complicidad incluso de algunos estamentos policiales.

Algunos de los trabajos que repasan los escándalos políticos, financieros y sexuales difundidos por los medios de comunicación durante las etapas de John Major y Tony Blair (Tumber, 2004), concluyen que el escándalo no sólo se ha convertido en un gran negocio para los periódicos sensacionalistas, sino que también ha influido sobre los diarios clasificados como serios. La consecuencia ha sido el incremento de la tabloidización en toda la prensa, con historias destapadas por los periódicos sensacionalistas y reproducidas luego por los diarios de gran formato. 
Todo ello combinado con el camino iniciado hacia la "Talk-Show Democracy", que ya se mostró la simpatía de Blair por programas como "Larry King Live", "Good Morning America" y otros formatos de infoentretenimiento televisivo frecuentados por Clinton. Blair fue pionero el líder laborista a la hora de comparecer en programas británicos muy similares, como "This Morning" o "The Frank Skinner Show", muy vistos "por un montón de gente que no sigue las Prime Minister's Questions (preguntas parlamentarias al primer ministro) ni lee los periódicos" (Castle, 1998). Del mismo modo, Blair fue entrevistado en el canal joven "Channel 4" y en el late-afternoon "Richard and Judy Show", muy popular entre las amas de casa y los votantes mayores, con la intención de hablar de las cuestiones importantes pero de un modo más informal y accesible.

Una forma más de entender el cambio en las estrategias de comunicación de los laboristas, pasando de las referencias a "nuestra gente" por las llamadas y mensajes "al pueblo" (Wring, 1996, p.105).

\section{Publicidad política en UK: Algunos antecedentes hasta los años 90}

La publicidad política fue pionera en USA, pero las técnicas del marketing y los estilos y formatos de los anuncios se adoptaron primero en el Reino Unido por los Tories (McNair, 2011, p.101), que también empezaron a emplear los spots de televisión en 1955, tras observar el éxito de la campaña de Eisenhower de 1952.

La campaña de 1955 ya incluía la emisión de piezas audiovisuales protagonizadas por el entonces candidato a Primer Ministro, Harold Macmillan, hablando de los nuevos vientos de cambio que soplaban en el Reino Unido de paz y por la fuerza y el progreso en el mundo, una pieza bajo el título "United for peace and progress", en la que incluso se aludía a las cartillas de racionamiento y sus efectos sobre los niños tras la gran guerra. $Y$ en 1959, los conservadores se convirtieron ele primer partido británico en contratar una empresa de publicidad comercial, Colman Prentis and Varley (CPV), para 
ejecutar una campaña por valor de 250.000 libras dirigida a la clase trabajadora.

Los conservadores ganaron las elecciones de 1959, pero perdieron la campaña de 1964, debido a las divisiones internas en el seno de los Tories y la desmoralización provocada, entre otros, por el caso Profumo, si bien volverían a ganar de nuevo en 1969, presentando varios anuncios, entre ellos, uno asociado al estilo narrativo del programa de la ITV "News at Ten" y otro jugando también con las convenciones de la publicidad comercial, presentando a un ama de casa cansada de la vieja marca (Labour) y decidida a probar el nuevo producto.

Durante los años setenta, desde los tiempos de Edward Heath como primer ministro hasta su relevo como líder por Margaret Thatcher, los conservadores contaron en sus gabinetes con distintos responsables de marketing que habían trabajado con la agencia de publicidad Saatchi and Saatchi, los cuales se encargaron de la elaboración de focus groups encaminados a la búsqueda de mensajes políticos dirigidos a los distintos segmentos de población.

Con la llegada de Jonh Major se observó que un cambio de liderazgo requería igualmente un cambio en la estrategia de comunicación, pues un gobierno que había estado en el poder durante trece años tenía que ofrecer algo nuevo, designando de nuevo a Saatchi and Saatchi para gestionar la próxima campaña, en un intento "de reconstruir la atmósfera creativa de campañas anteriores" (Butler and Kavanagh, 1992, p.35).

La agencia utilizó los métodos de investigación cualitativa y los resultados del estratega americano y asesor de Ronald Reagan, Richard Wirthlin, quien observó que las preferencias de los votantes fluctuaban en las personalidades y las políticas, mientras que los valores eran más estables. Y así, a través de la realización de una serie de entrevistas en profundidad, la compañía observó que los valores más importantes que el electorado buscaba en los partidos fueron esperanza, seguridad y paz. 
Sobre la base de estas investigaciones, Saatchi and Saatchi desarrolló una campaña publicitaria que hacía hincapié en la fuerte reputación del partido en la gestión económica, evitando al mismo tiempo perder terreno en la cuestión social, elegida por los laboristas para su campaña. Con tal fin, se presentó una publicidad indicando que con los laboristas se pagaban 1,250 libras más de tasas al año y utilizando la imagen de una bomba cayendo.

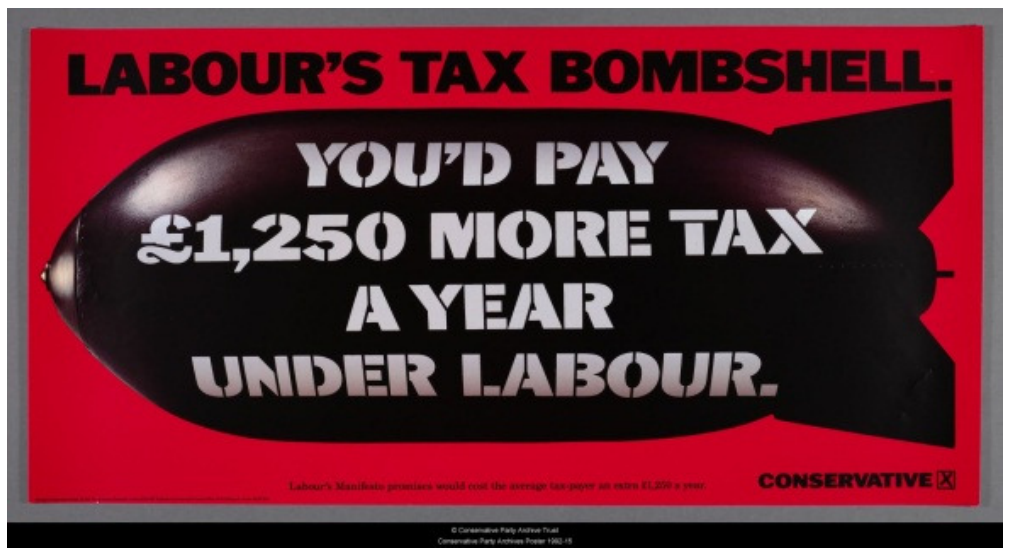

En el terreno audiovisual, el anuncio más memorable de la campaña de 1992 de los conservadores se adaptaba a la categoría de cinema verité de la publicidad política, con un John Major viajando de vuelta a sus raíces desde el asiento trasero de su coche oficial por las calles de Brixtol y Londres, bajándose a hablar con la gente corriente en las calles y el mercado y mostrando su "espontánea sorpresa", al pasar delante de su antigua casa. Sin embargo, la pieza (titulada "John Major, the Movie"), cumplió con su propósito de mostrar sus orígenes de baja clase media social a un público harto de trece años de una Margaret Thatcher de grandeza altiva.

\section{Estrategias y campañas: de Tony Blair a David Cameron}

\subsection{El primer cambio: las elecciones de 1997}

Las elecciones de 1997 supusieron un punto de inflexión para los laboristas, tras catorce años en la oposición, como consecuencia de lo que se consideró una traición de esta formación a sus partidarios y, en particular, a la clase obrera. Los laboristas, que perdieron las elecciones de 1983, habían atacado 
los valores de los trabajadores y la clase media y acusaban una pérdida de identidad, convirtiéndose en el partido del extremismo, de las huelgas, la inflación, los impuestos, la indisciplina y falta de unidad (Gould, 1998, p.4).

Pero con la profundización en la investigación y la utilización de las estrategias y técnicas del marketing y la comunicación, el Partido Laborista asentaría las bases no sólo para recuperar el poder en las elecciones de 1997, sino también para mantenerse en el mismo durante varias legislaturas.

Así, el partido ya había comenzado a trabajar, años antes de las elecciones de 1997, en el diseño de grupos focales, a través de los cuales detectó cuatro cuestiones básicas: que el Partido Laborista se juzgaba por su pasado (frases asociadas con descontento, influencia de los sindicatos, huelgas, inflación), que los valores asociados al partido eran negativos (impuestos, injusto imparto de la riqueza y la propiedad), que se observaba como hostil a las familias, la gente ahorradora, los pensionistas y los emprendedores empresariales y, en cuarto lugar, que los laboristas ya no eran el partido de la clase trabajadora.

Este era el panorama cuando Tony Blair se convirtió en líder del partido, en 1994 y, a partir de entonces, Philip Gould, como estratega de la formación, buscó la reconstrucción de la formación planteando un nuevo partido, con nuevos principios de campaña y una nueva organización y propósitos políticos. La búsqueda de un reposicionamiento a través del realismo político resumido en un lema: "New Labour, New Britain".

El partido planteó diez nuevos principios de campaña y, desde el punto de vista de la comunicación, propuso trabajar con las noticias, en lugar de contra ellas, entendiendo que no tenía sentido luchar en contra de la agenda de los medios, sino aprovecharla. En cuanto a la publicidad, se acordó buscar un balance de lo positivo con lo negativo, entendiendo que el electorado no aceptaría ataques negativos que no estuviesen equilibrados con temas y mensajes positivos.

Poner la sustancia antes que el estilo y el contenido antes que la forma y advertir que las palabras debían acompañarse de hechos, fueron otros de los 
objetivos, tras observar que el electorado quería una política real, de verdadero cambio y compromiso.

Un nuevo partido significaba también una nueva organización y estructura, con la dotación de un comité de dirección de campaña (War room) más ejecutivo, compartiendo el mismo espacio físico y monitoreando constantemente la actividad de la oposición, para que cualquier ataque pudiese ser contestado de forma inmediata, y manteniendo un diálogo constante con el electorado.

A partir de entonces, los conservadores comenzaron a reaccionar, presentando una publicidad ("Dolió, pero funcionó") a modo de disculpa de los sacrificios realizados durante sus años de gobierno, y pasando directamente al ataque a los laboristas, con su eslogan "New Labour, New Danger" (Nuevo Laborismo, nuevo peligro). Los laboristas, contentos de la reacción de sus adversarios, por meterles en campaña y reconocerlos como un peligro potencial, contestaron indicando que "Gran Bretaña se merece algo mejor".

Pero muchas cosas cambiaron en la política británica entre 1992 y las siguientes elecciones, celebradas en 1997, con los conservadores dañados por escándalos sexuales y financieros del partido y con evidentes divisiones internas en el seno del partido sobre la política de la Unión Europea, con los problemas de la Unión Monetaria y la devaluación de la libra.

La credibilidad del gobierno de John Major había sido cuestionada en 1992, por la salida de la libra del ERM (European Rate Mechanism), del que Major había persuadido a Thatcher parar entrar un par de años antes. $Y$ aunque los laboristas habían votado inicialmente en contra de la entrada en Europa, con la llegada de Blair se convirtió en una apuesta decidida. En 2003 decidieron posponer la entrada, pero Europa seguiría siendo un objetivo para el partido, tal y como reconocía Derek Scott (2004, p.64), uno de sus asesores económicos.

Una serie de cuestiones, en definitiva, que provocaron un voto contra los conservadores en 1997, más que contra el conservadurismo, tal y como indicó uno de los analistas del partido (Finkelstein, 1998, 12). Ante tal panorama, quedaron sin efecto los intentos de acudir de nuevo a la publicidad negativa 
con el ánimo de retratar a Blair con ojos de diablo, o de mostrarlo como títere del entonces canciller alemán, Helmut Khol, sentado como una marioneta sobre su regazo, con la intención de explotar la política relativamente proeuropea de los laboristas.

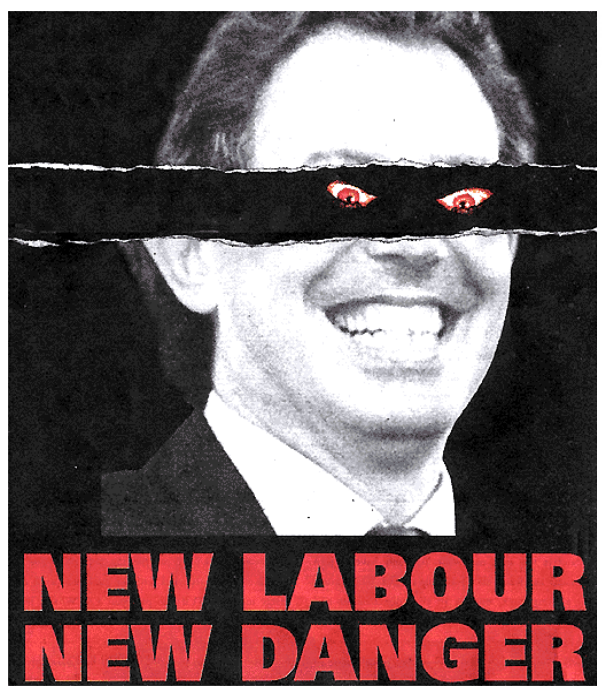

\section{LABOUR'S POSITION ON EUROPE.}

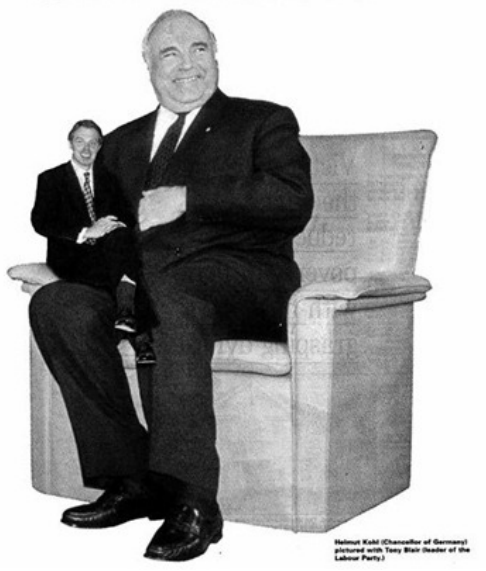

$Y$ con el fin de afianzar los votantes cambiantes (switchers) del partido Tory, los laboristas decidieron explotar las debilidades de sus adversarios (sobre todo sus resultados económicos y el incremento de los impuestos sobre la clase media), así como las fortalezas de Blair, frente a la ruptura de las promesas realizada por John Major. Otro de los objetivos de la campaña laborista fue tranquilizar a la gente mostrándole que las políticas de los laboristas eran sensatas y moderadas.

Por su parte, los conservadores observaron que existía un gran abismo entre la realidad de una economía saneada y halagüeña, que suponía un buen aval para cualquier gobierno que se presente a una reelección, pero que contrastaba con la imagen de un partido dividido y enfrentado. Los hechos se enfrentaban a la imagen, por mucho que tratasen de retomar el mensaje de la época de Harold Macmillan, a finales de los años cincuenta, de que "la vida es mejor con los conservadores" y "no deje que los laboristas se la arruinen", jugando incluso con la imagen de un modelo que se mostraba en posición 
insinuante, una campaña promovida por el grupo LGBTory, una organización de defensa de los derechos homosexuales vinculada al partido.

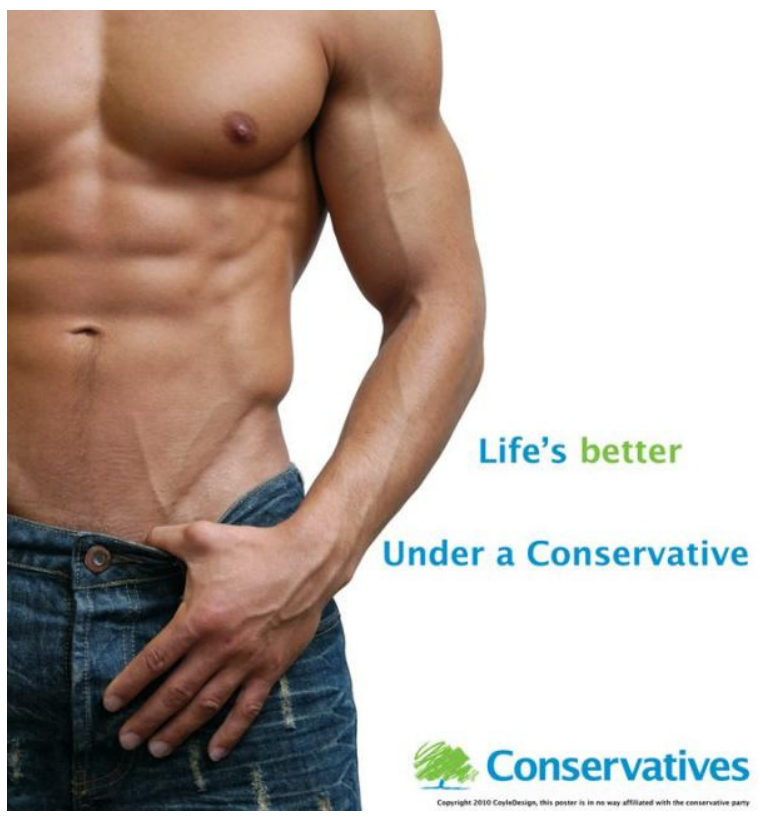

Aun así, los Tories seguían siendo vistos como un partido eficiente pero indiferente a los cambios que se estaban produciendo en la sociedad británica y los nuevos retos y problemas que afrontar, siendo víctimas de sus propios éxitos, al reconocer que el partido había cambiado la cultura del país, pero no logró adaptarse a esos cambios.

Pero a pesar de los éxitos electorales cosechados a partir de 1997, el Partido Laborista se había mostrado, inicialmente, muy reticente al empleo de la publicidad comercial, en contraste con los conservadores, que acudían sin complejos a la aplicación de unas técnicas y herramientas del marketing que los laboristas observaban como una especie de traición ideológica, al desconfiar de la publicidad como una empresa capitalista.

Una cuestión contra la que tuvieron que luchar las agencias encargadas de la publicidad laborista, entre ellas Bartle, Bogle y Hegarty (BBH), a las que incluso se impidió que participaran en las reuniones de estrategia del partido, hasta que abandonaron la táctica de intentar ganarse al electorado en la calle, a través de manifestaciones públicas, a contratar una agencia, Boase Massimi 
Pollit (BMP), que había trabajado para los sindicatos, con la intención de aplicar la investigación de mercado comercial al terreno electoral.

Imbricaciones que continuarían en 1985, con la designación de Neil Kinnock como nuevo líder del Partido Laborista, quien nombró al productor de televisión, Peter Mandelson como director de comunicación de la campaña electoral, quien a su vez contrató a un ejecutivo de publicidad, Philip Gould, para llevar a cabo una revisión de las técnicas electorales de los laboristas. Kinnock enfocaría los manifiestos electorales del partido desde el "tiempo de trabajo" y de conseguir que Gran Bretaña "vuelva a funcionar de nuevo" ("Time to get Britain working again"), jugando retóricamente con la terminología afín a la denominación del partido, hasta llegar, en 1992, a un mensaje de "Time for Change" prematuro, ya que los conservadores volverían a ganar las elecciones generales por cuarta vez consecutiva, pero premonitorio de la posterior victoria de Tony Blair, en 1997.

Gould, como ideólogo y arquitecto del Nuevo Laborismo, observaría la coincidencia del proceso con la campaña y el ascenso de Bill Clinton en USA, adaptando la estrategia de la "triangulación" planteada por el asesor americano Dick Morris ${ }^{3}$, al caso inglés, con el surgimiento de la denominada "Tercera Vía".

La aplicación de esta estrategia se observo en la promoción de un video de Blair en cuyo inicio y final se utilizó la imagen de un bulldog inglés, símbolo patriótico (utilizado también por el nacionalismo británico antieuropeísta), para tratar de atraer a los votantes conservadores de clase media y mantener, al mismo tiempo, a los votantes laboristas.

En estas elecciones también los liberal-demócratas basarían su estrategia en dos objetivos: segmentación del electorado (targeting) y búsqueda de escaños clave, con un plan de desarrollo regional, y captación de fondos (fund-raising), además de combatir la impresión de que "nadie sabe lo que representan" (Holme, 1998, p.18) y de centrarse en temas abandonados por laboristas y conservadores, como el medioambiente y la educación. En este sentido, jugaron con el color corporativo del partido, el amarillo, para presentar a los ciudadanos un gran queso "Cheese", en el que cada letra significaba un área 
temática de interés para el partido: el combate de la criminalidad y la sordidez (escándalos) y la defensa de la salud, economía y educación. $Y$ a pesar de sus debilidades, los liberal-demócratas contaban con una gran fortaleza, que fue la alta valoración y popularidad de su líder, Paddy Ashdown, el de mayor confianza entre los votantes de los tres partidos.

\subsection{Las elecciones de 2001 y 2005: ni adelante ni hacia atrás}

Los siguientes procesos electorales británicos, del 2001 y 2005, fueron de transición, definida a través de mensajes que apelaban a la vuelta al pasado 0 el camino hacia el futuro. Así, los laboristas pasaron del "It's time for a change" (es tiempo de cambiar) de 1997, a la petición de "Give us more time" (danos más tiempo) del 2001, hasta que llegaron los comicios del 2005 y Tony Blair indicó que tenían "que ganar por sus propios méritos" y el primer ministro, que aspiraba a renovar su puesto, quería sentirse "liberado para gobernar en nuestros propios términos" (Milburn, A, 2004).

Como consecuencia de ello, los laboristas plantearon una campaña para, primero, asegurar la renovación de su mandato frente a los conservadores y, en segundo lugar, para marcar su dirección, de ahí el mensaje de "Forward, not back" (adelante, no atrás), conveniente para ambos casos (Fielding, 2005, p.27).

En los comicios celebrados en 2001, el ascenso y victoria de los laboristas se había fundamentado sobre las cuestiones relacionadas con la salud y la educación, contra la que tampoco pudo hacer nada la publicidad de los conservadores, diseñada por la agencia Yellow $M$, mostrando la longitud de la lista de espera de un hospital o el tamaño de las clases de una escuela.

Unas elecciones en las que los laboristas también presentaron varias piezas, diseñadas por la agencia TWBA en Londres, combinando piezas en positivo en las que se respondía a la pregunta de si había cambiado el Reino Unido desde 1997, con otras de publicidad negativa invitando a los votantes, a través de una serie de películas de desastres, a imaginar las consecuencias de la vuelta al 
poder de los Tories. Otra pieza utilizaba una serie de imágenes digitales para retratar al entonces líder de los conservadores, William Hague, como un clon de Margaret Thatcher, una constante manejada por el New Labour en diversas campañas.
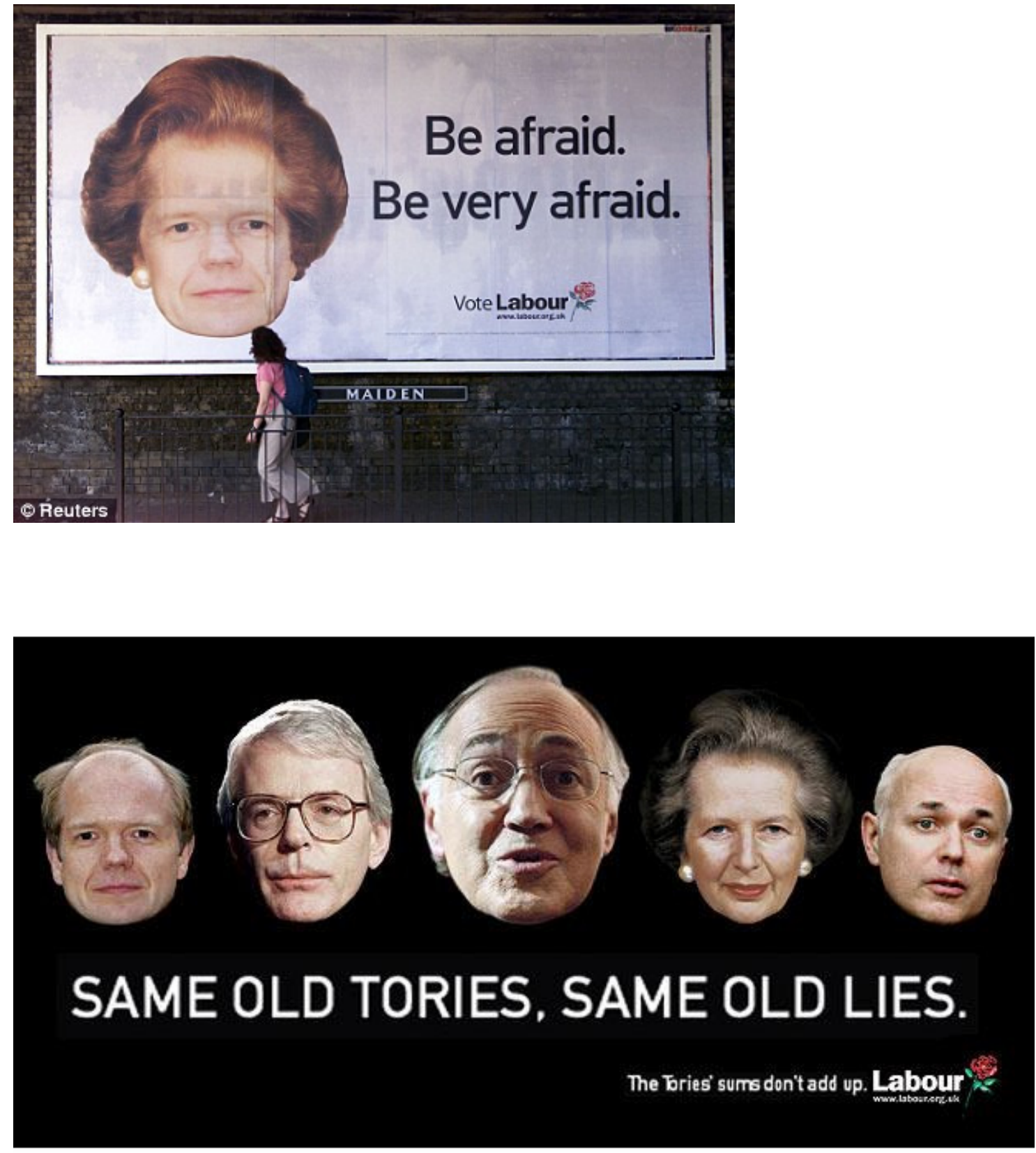

Posteriormente, las elecciones de 2005 se resolverían con una campaña de bajo perfil por parte de ambas formaciones, en la que los conservadores reconocían que el Reino Unido era un gran país, pero podía ser mejor, 
haciendo hincapié en la necesidad de aumentar los controles de inmigración y mejorar los servicios públicos.

Por su parte, los laboristas instaron a los votantes a renovar su confianza en esta formación por el bien de la estabilidad que conduce al crecimiento, al tiempo que se indicaba al electorado que Gran Bretaña estaba trabajando, pidiéndole que no permitiese que los Tories llevasen al país de nuevo a la ruina ("Britain is working. Don't let the Tories wreck it again").

Un eslogan llevado hasta el extremo de mostrar a los dirigentes conservadores, William Hague y el canciller Oliver Letwin, como cerdos voladores, lo cual provocó una protesta por parte de la comunidad judía, al considerar que se trataba de una pieza antisemita, teniendo en cuenta además las connotaciones del animal para esta comunidad como ser impuro e inferior.

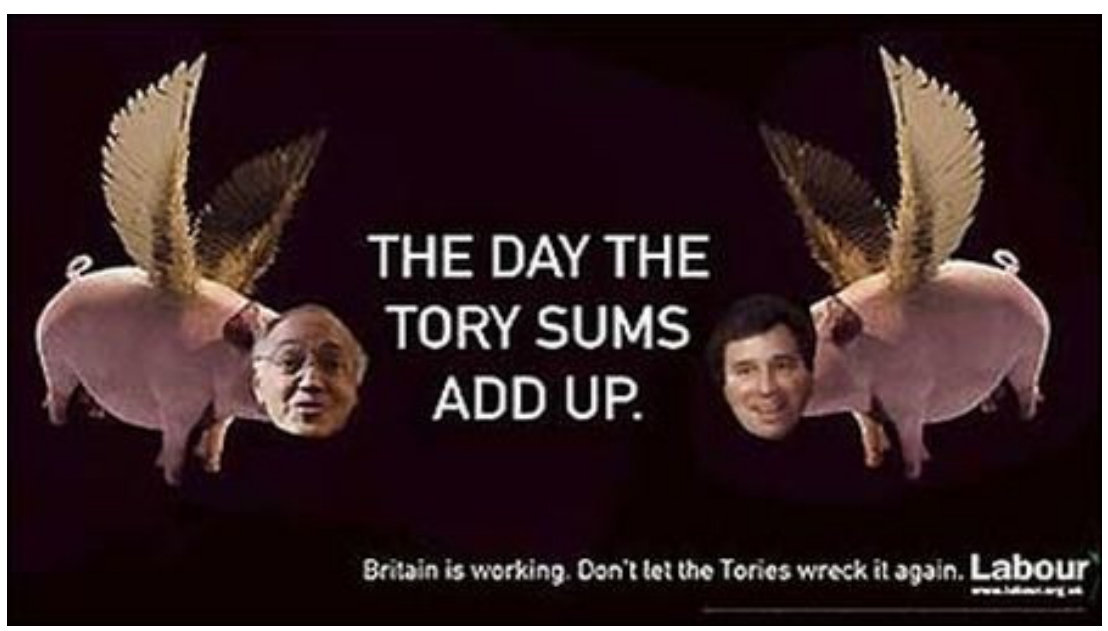

Pero detrás de la publicidad hubo un debate ideológico de fondo, a lo que se añadieron algunas críticas sobre la gestión y actuación del último período de los laboristas, que provocaron una victoria muy ajustada de Blair, como consecuencia de lo que había sido un referéndum sobre el primer ministro.

La idea de un "New Labour" nunca había sido plenamente aceptada por el partido, pues una parte del mismo pensaba que la búsqueda de votantes del "middle England" (la clase media inglesa) los había convertido en unos entusiastas incondicionales del libre mercado, con poca consideración por la reducción de la desigualdad (Fielding, 2003) y el incremento de la pobreza en las familias y los pensionistas (Hills and Stewart, 2005). 
Esta fue la otra cara de la moneda del "implacable centralismo" y la "hegemonía política" (Denham, Garnett and Dorey, 2011, p.24) lograda por Blair, como una gran carpa que podía dar cabida a la inmensa mayoría de los votantes. De hecho, Blair incluso llegó a utilizar la palabra "conservador" para evocar lo que algunos sectores progresistas consideraban el "nasty party" (partido repugnante) y a la vez distraer la atención de los críticos que le estaban atacando por su supuesta adhesión a los principios neoliberales.

Y aparte de la frustración expresada por algunos miembros del partido por la falta de dirección, las críticas también vinieron por el apoyo del primer ministro a las intervenciones de Afganistán e Irak, una decisión que minó su credibilidad. Sobre todo cuando se supo que el director de comunicación de su gabinete, Alastair Campbell, había presionado a los medios para tratar de impresionar a un público escéptico con la intervención, exagerando deliberadamente la amenaza de Saddam y presentando un expediente a la Cámara de los Comunes asegurando que Irak podía desplegar armas de destrucción masiva en 45 minutos.

Tales eran los problemas, que en el año 2003 Blair incluso llegó a discutir con su número dos, Gordon Brown, sobre la posibilidad de renunciar en su favor antes de las siguientes elecciones (Bower, 2005, p.434). Sin embargo, luego decidió seguir adelante y, en 2004, remodeló su gabinete y nombro a Alan Milburn como coordinador de su campaña, quien se centró en lanzar mensajes destacando los logros económicos del gobierno y la amenaza que supondrían los conservadores para la estabilidad del país (Cowley and Green, 2005, p.39).

Pero el rostro sonriente de Blair ya no estaba presente en la campaña planteada en esta ocasión. Los laboristas diseñaron una campaña de ataque profundizando en la idea de que si uno de cada diez de sus votantes no acudía a las urnas, su contrincante, el conservador Howard, se metería en el número 10 de Downing Street, planteando con tal fin una publicidad que recordaba el paro y los embargos que se produjeron durante la década de los noventa, dirigida a los votantes que eran niños en aquel momento. 
Aun así, Michael Howard se convertiría en el cuarto líder conservador despedido por Blair, a pesar de los esfuerzos realizados por Lynton Crosby, un australiano traído por el candidato Torie para dirigir su campaña, centrada en alentar a los votantes a usar su voto como una protesta o una forma de enviar un mensaje. Los conservadores diseñaron una publicidad en la que contestaban al "adelante, no atrás" de los laboristas con la llamada a imaginarse "cinco años más de esto", utilizando para ello una serie de recortes de titulares de prensa negativos sobre la gestión de sus adversarios en el gobierno.
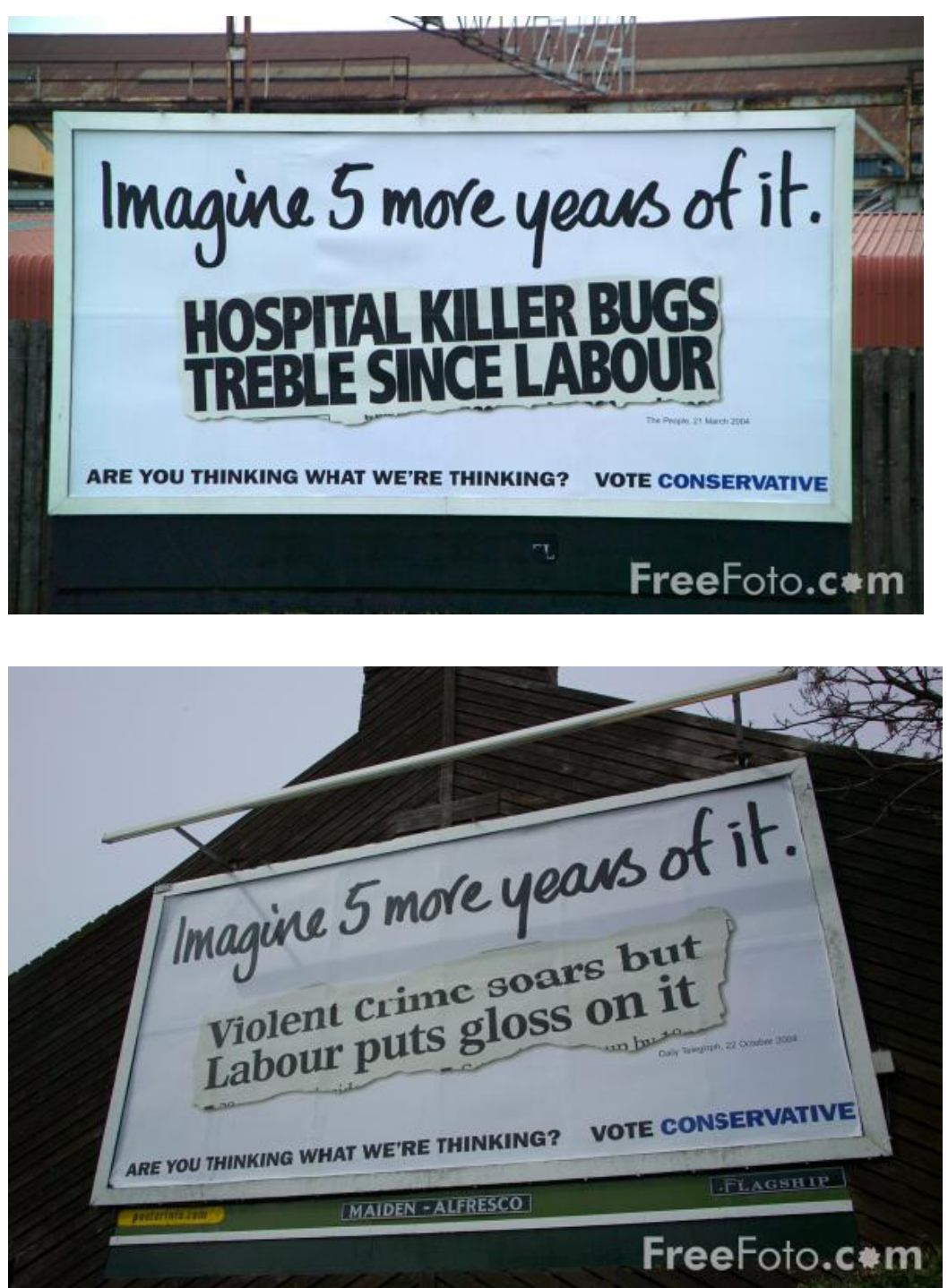


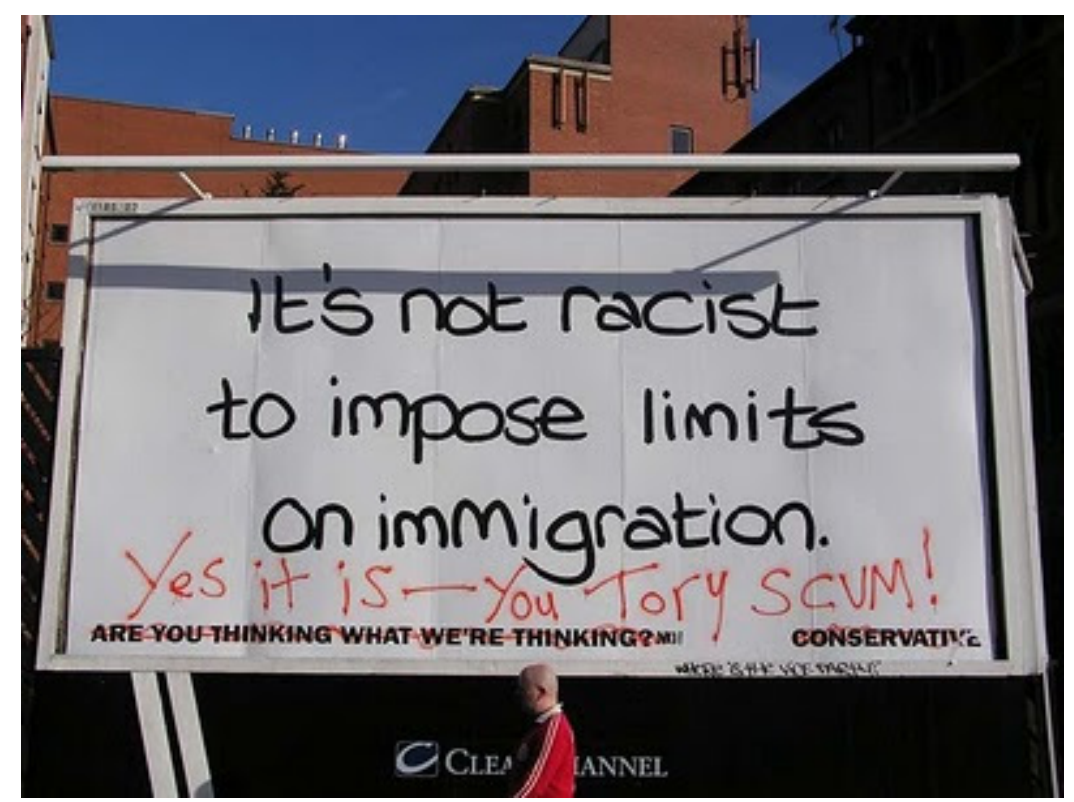

Una publicidad centrada en aspectos como la sanidad, la delincuencia o la inmigración, tal y como se puede observar en las piezas anteriores, algunas de ellas respondidas con el mismo estilo al empleado por los conservadores.

Por su parte, los liberal-demócratas obtendrían un estimable incremento de escaños en estas elecciones, a costa de la desilusión hacia el gobierno, el temor a las medidas de los conservadores y la mejor valoración de Charles Kennedy, su líder, frente a Blair y Howard. De hecho, después de una serie de intervenciones competentes en varias entrevistas realizadas en televisión, Kennedy obtuvo los mejores resultados de liderazgo frente a sus oponentes tras su intervención en el programa de la BBC "Question Time". Afirmó que Blair sería un "pato cojo" como presidente y acusó a los conservadores de titubear a al hora de posicionarse sobre la subida de los impuestos municipales, aparte de criticar el apoyo de unos y otros a la guerra de Irak.

\subsection{El último cambio: Las elecciones de $\mathbf{2 0 1 0}$}

Blair conseguiría llegar al poder y mantenerse, hasta su sustitución por Gordon Brown, víctima de las protestas y hostilidad hacia el gobierno por el incremento de los impuestos y la disminución de los ingresos de los hogares y acosado por los medios por el escándalo, entre otros, de los excesivos gastos descubiertos 
de los parlamentarios, así como por el decidido apoyo que su antecesor había dado a la guerra de Irak. De hecho, los cálculos realizados por los estrategas del Partido Laborista indicaron que los votantes que cambiaron de este partido a los liberales demócratas fue, aproximadamente, de un millón de electores (Cook, 2011, 129).

La "luna de miel" inicial de la que disfrutan todos los gobernantes cuando llegan al poder, dio paso a la solidaridad con el gobierno de Brown ante los primeros reveses económicos, entre ellos la crisis del sector bancario y el rescate realizado en octubre de 2008 , hasta finalizar con la hostilidad hacia los laboristas, tal y como mostraba la evolución de las encuestas en este período (Kavanagh and Cowley, 2010, p.167).

Un cúmulo de circunstancias contra las que poco pudo hacer la publicidad, ampliamente difundida a través de Twitter y Facebook, que trataba de sacar partido a las críticas sobre la personalidad de Brown como hombre seco y duro, mostrándolo como "Harry el sucio" (tal y como reconocieron los diseñadores de la campaña), que pedía al "niño pijo" de David Cameron que saliese fuera ("Step outside, posh boy"). Una publicidad con la que los laboristas pretendían provocar el debate televisado con el líder conservador y, al mismo tiempo, movilizar a los votantes de izquierdas más apáticos con la política.

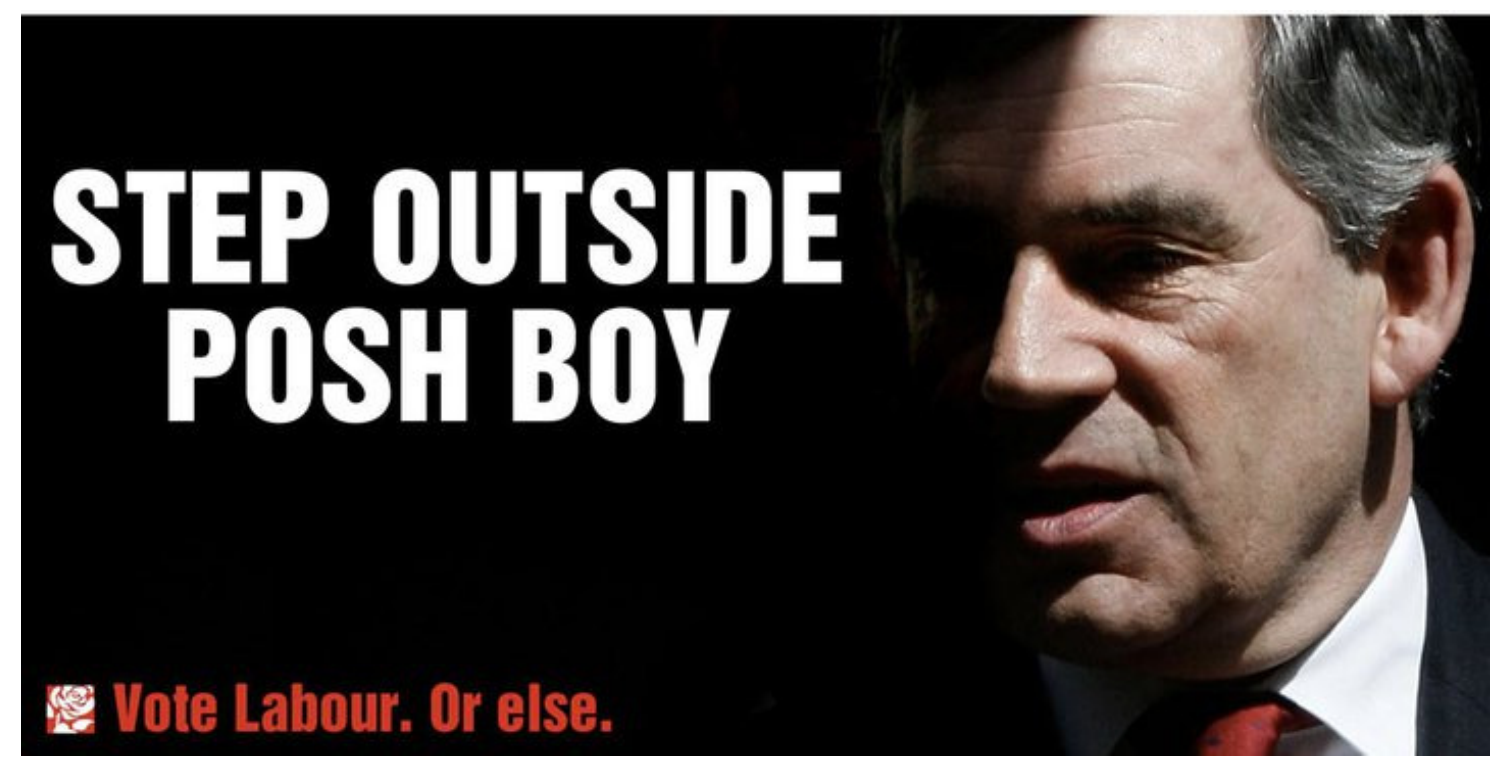


Las elecciones de 1997, 2001 y 2005 habían supuesto los tres peores resultados de los conservadores, en términos de porcentaje de votos y número de escaños. El partido observó la necesidad de aplicar una estrategia de reparación de la marca (Wilson, 2011, p.148), consciente de que ésta no sólo se creaba por la "shopping list" de las promesas electorales, sino que era algo más profundo, reflejado a través de los valores, credibilidad y competencia política y la capacidad de identificarse con las preocupaciones, aspiraciones y deseos de la gente común.

Los tories eran observados como un partido desconectado y obsoleto. Sus investigaciones mostraban que, aunque eran muchos los decepcionados con el gobierno Laborista, todavía eran más los que no estaban seguros de que los conservadores fuesen una alternativa creíble y que el partido no había cambiado desde 1997 o incluso había cambiado para peor.

Cameron reconoció la magnitud del desafío y creó una plataforma de "cambio para ganar" dirigiéndose en la conferencia del partido a las cuestiones relevantes para la gente actual, cómoda con un país moderno, para lo cual se crearon comisiones con la intención de tomar partido en áreas que tradicionalmente no eran vistas como territorio torie, en cuestiones como la mejora del servicio público, la calidad de vida, la pobreza mundial, la globalización y la justicia social. Incluso colocaron la preocupación sobre el medioambiente en el corazón del pensamiento del partido, como lo demuestra el mensaje "Vote Blue Go Green", empleado ya en las elecciones locales del año 2006.

"Nosotros cambiamos nuestro partido y podemos cambiar nuestro país", era alguna de las consignas lanzadas por los conservadores en su publicidad impresa y audiovisual, tras observar la necesidad, primero, de un cambio interno en el partido, empezando por el procedimiento de selección de sus candidatos, fijando nuevos temas dentro de la "priority list" del partido, más allá de las viejas polémicas sobre Europa, la inmigración y los impuestos. Esto sirvió para que los conservadores se diesen cuenta de que no estaban haciendo campaña sobre los temas que eran más importantes para los 
votantes, observando la pérdida de reputación del partido en competencia económica y la preocupación que existía sobre si podrían ser confiables para cuidar los servicios públicos.

Como consecuencia, en el 2008 los conservadores vieron que su posición sobre los atributos clave de marca ("key brand") había mejorado con respecto a los laboristas, así como en la comparación entre David Cameron y Gordon Brown.

Pero la campaña para las elecciones generales comenzó meses, e incluso años antes del anuncio formal del entonces primer ministro, Gordon Brown, de la fecha de las elecciones y, en el caso de los conservadores, comenzó tan pronto como David Cameron se convirtió en líder de su partido, en 2005, con la designación de Steve Hilton como jefe de estrategia y, más tarde, Andy Coulson, editor de News of the World, como director de comunicación. Los tories también romperían con $M C$ Saatchi, encargada de la publicidad del partido en las tres últimas citas electorales, en favor de la agencia EURO RSCG.

De las primeras piezas publicitarias difundidas, tanto en soporte impreso como audiovisual ${ }^{4}$, fue la imagen de un bebé del que se indicaba que heredaba "la nariz de papá, los ojos de mamá y la deuda de Gordon Brown”, un anuncio al que siguió otro con un niño escribiendo en una pizarra y respondiendo a la pregunta de si la deuda había crecido o no. 

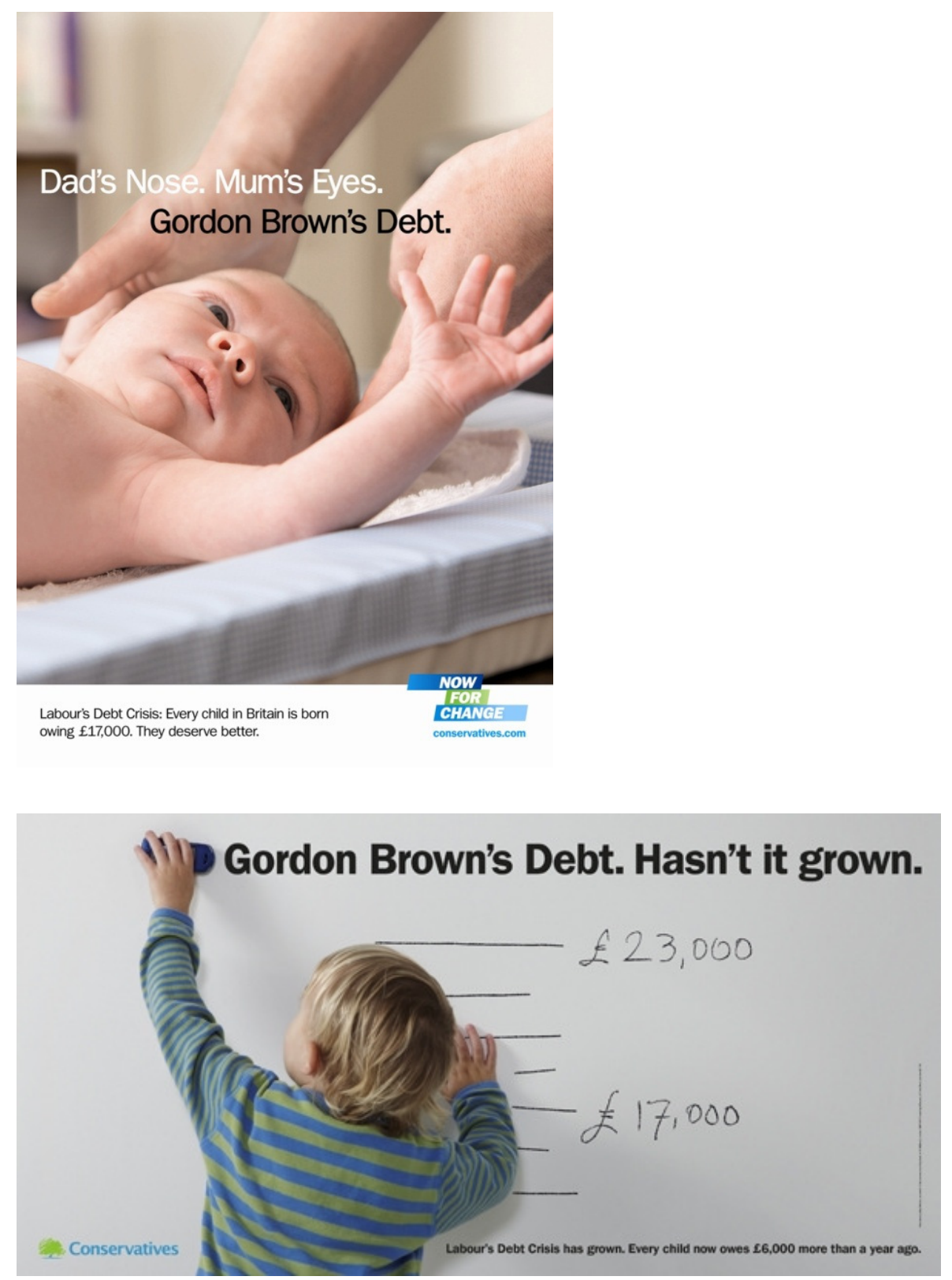

Pero el tiempo de cambio anunciado años antes por los laboristas en sus eslóganes sería, curiosamente, el que comenzaría a defender, seis meses antes de la celebración de las elecciones, el propio David Cameron, posando en los carteles con traje informal y camisa de cuello abierto y entrando en el terreno de los votantes de izquierdas, asegurando que "nosotros no podemos seguir así" y que cortaría el déficit, pero no el sistema de salud pública. Mensaje e imágenes muy atacadas y alteradas por sus detractores (cambiando, por ejemplo, su pelo engominado por un aspecto de "skin" con cresta), sobre todo a través de internet y la publicidad exterior, con actos que 
para unos representaban vandalismo político y para otros simplemente una forma un tanto irónica y contestataria de contrapublicidad.

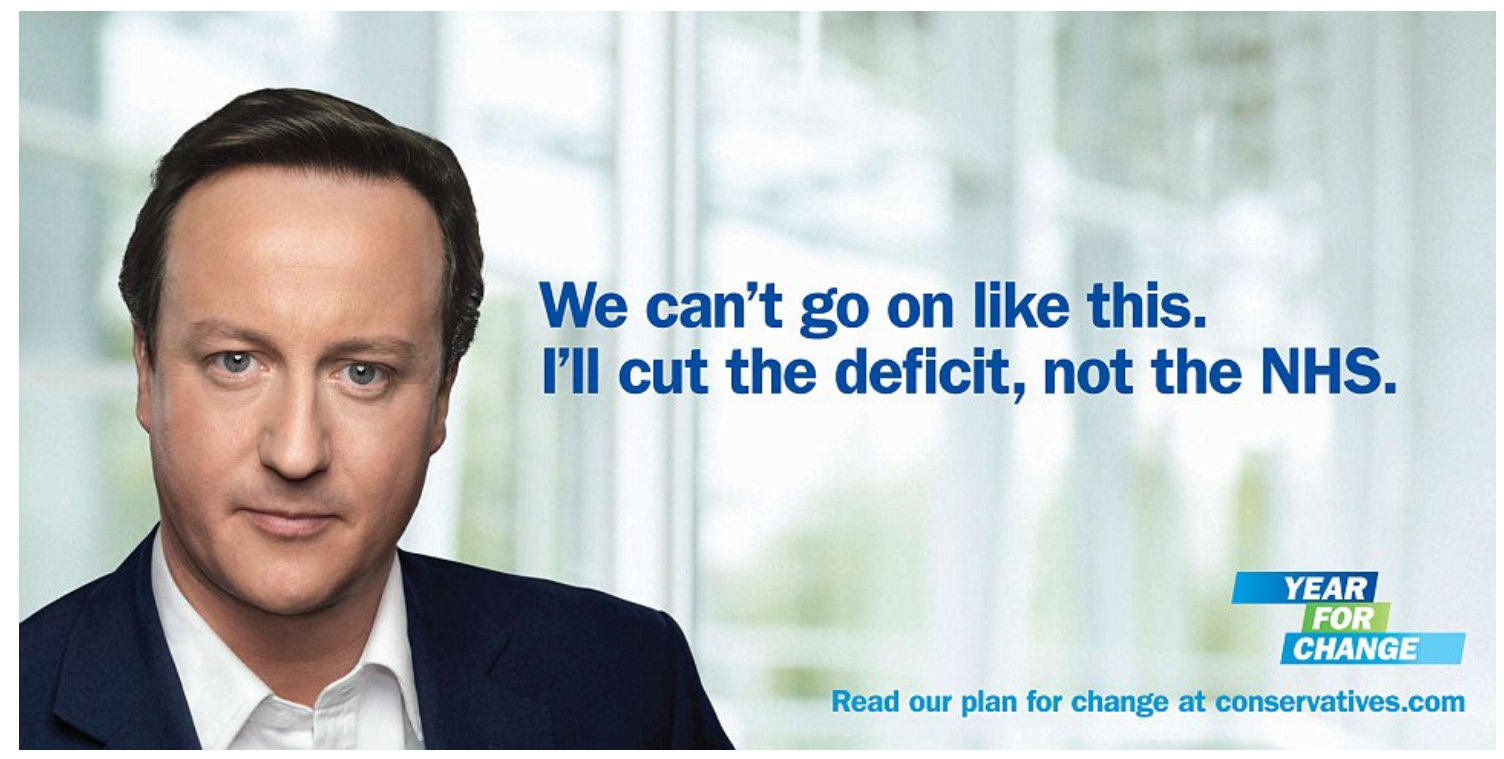

Algunas de las respuestas a esta publicidad se mostraron a través del sitio www.mydavidcameron.com, que recreaba distintas versiones, una página que recibió 252.641 visitas en sus seis primeras semanas.

Un mes después, en febrero, los conservadores lanzarían otra publicidad criticando un presunto plan de los laboristas de cobrar un impuesto a los familiares de las personas fallecidas, a fin de pagar por la atención recibida durante su vejez. Una pieza bastante criticada por "desagradable, impertinente y un cobarde intento de asustar a la sociedad" con el que Cameron "debería avergonzarse de tal propaganda negra" (Richardson, 2010).

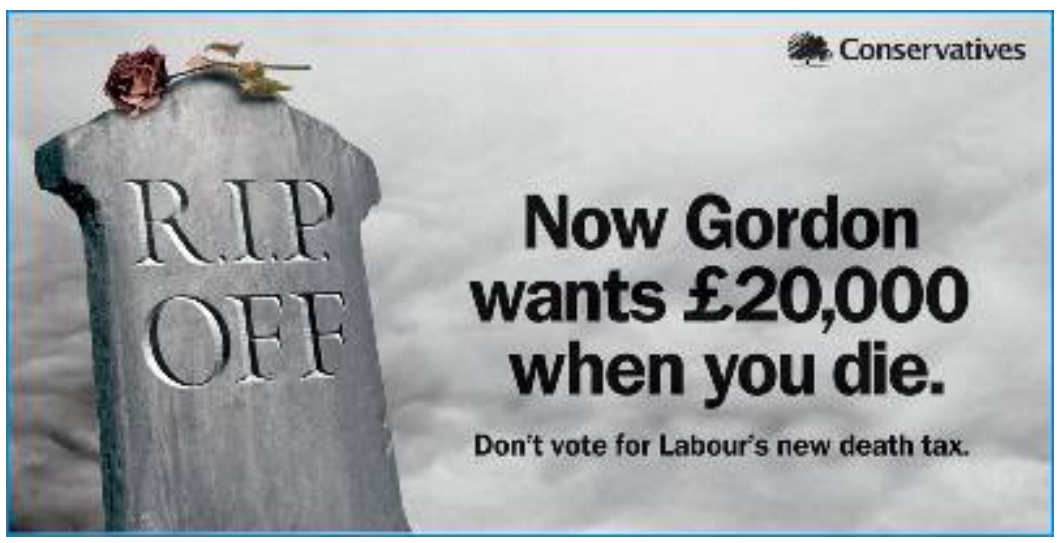


Pero los conservadores también difundirían una campaña en positivo dirigida a todos aquellos que no les habían votado en las elecciones anteriores, con tres tipos de protagonistas procedentes de tres localidades distintas: Julie, una madre de Llandudno, en Gales, que indicaba que le gustaban los planes del partido para ayudar a las familias; lan, un obrero de Congleton, una localidad del condado de Cheshire, que reclamaba atención sobre la economía, y Danielle, una joven negra de Brighton, ciudad costera del sur de Inglaterra, quien hacía una llamada a "arreglar nuestra sociedad rota".
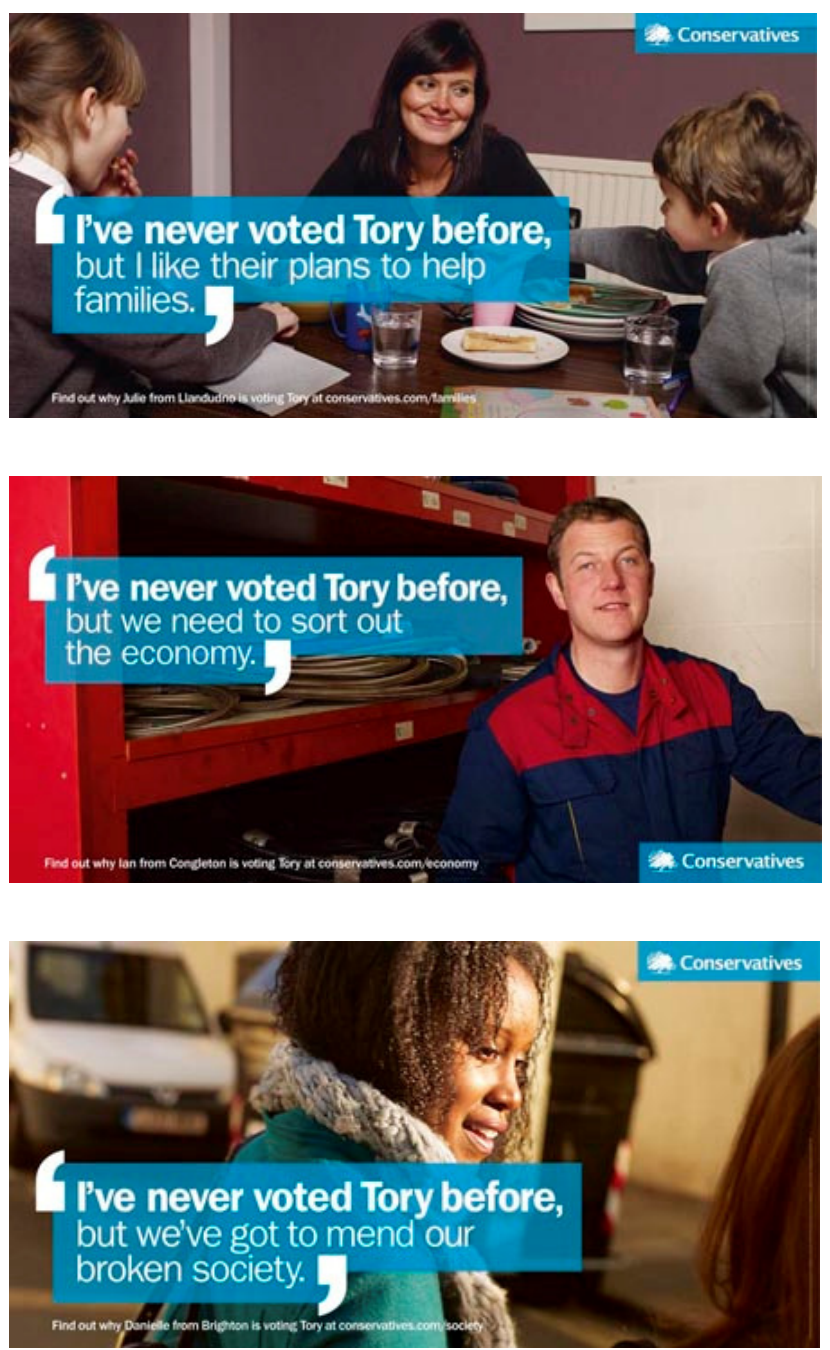

Una publicidad rápidamente contestada, incluso, desde su lanzamiento en la red donde, en cuestión de minutos, ya pudieron observarse distintas versiones trucadas, gracias a la facilidad para editarlas, utilizando las herramientas más básicas y sencillas, provocando la apertura de páginas de contestación a través de Facebook y Twitter ${ }^{5}$. Un nuevo debate sobre si el cartel, como recurso 
publicitario, había muerto, al socavarse su eficacia (Mcsmith y Norris, 2010), o si estas reacciones adversas generaban más publicidad para los conservadores.

Se difundieron nuevas campañas de publicidad negativa, con la utilización del rostro sonriente de Gordon Brown asegurando que "yo causé el record de paro juvenil", así como otra campaña en la que unas botas pisaban el primer brote verde de la recuperación económica.

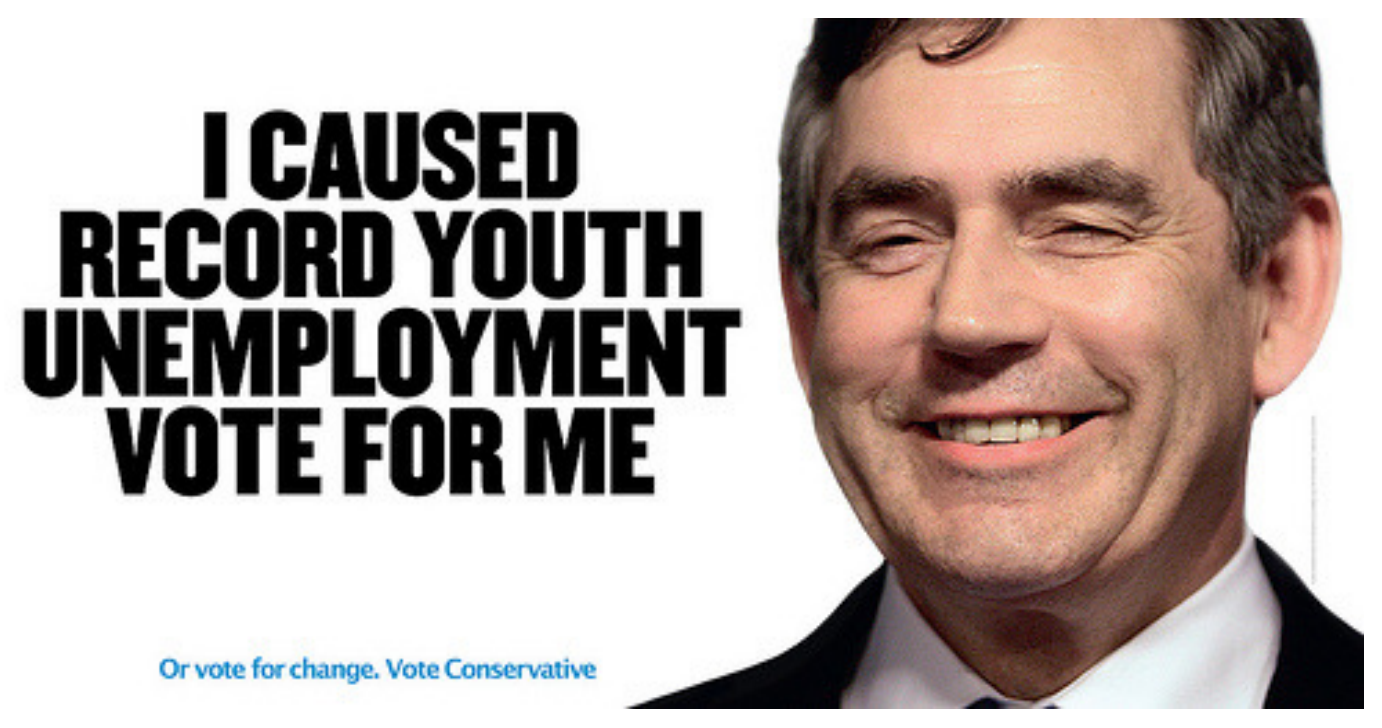




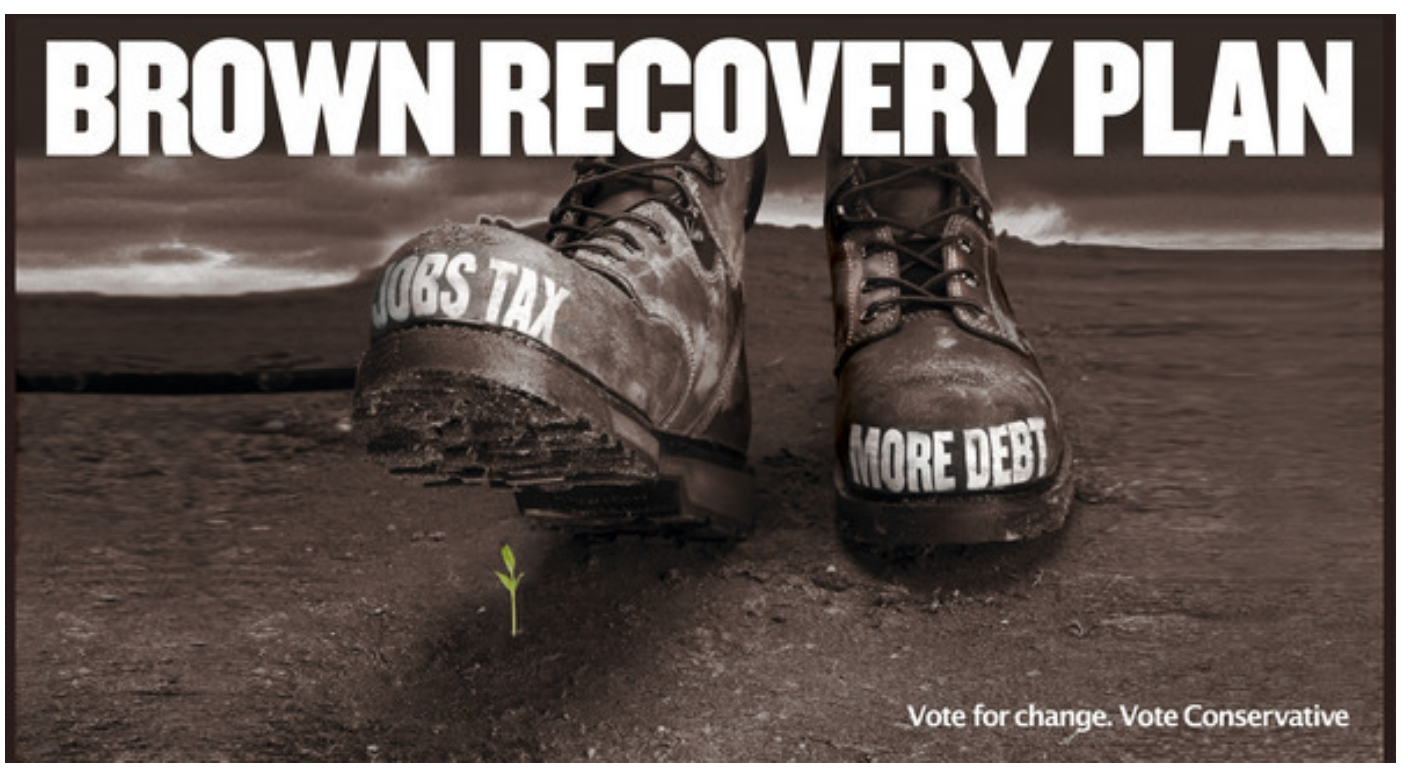

Los conservadores también recurrieron a la utilización de iconos visuales tradicionalmente asociados a la izquierda, con mensajes de agitación y protesta, con el ánimo de movilizar a la "gran sociedad" evocada por Cameron en sus discursos, y llamando a devolver el poder a la gente, muy en línea con la potenciación de la acción política a través del voluntariado social también fomentado por el partido.

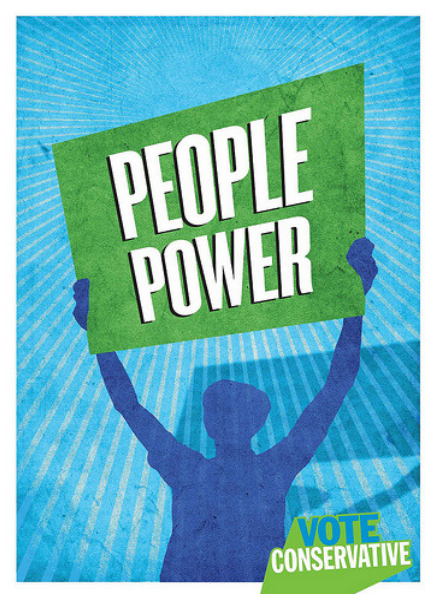

Finalmente, los Tories promovieron la difusión de publicidad con distintos mensajes (entre ellos uno que indicaba que acabarían con los beneficios y ayudas a quienes no quieren trabajar) con la intención de cuestionar algunas de las injusticias e incoherencias del Estado de Bienestar (Hoskin, 2010), con 
la imagen de la sociedad detrás de un Cameron que se mostraba dinámico y con la camisa remangada, listo para la tarea que tenía por delante.

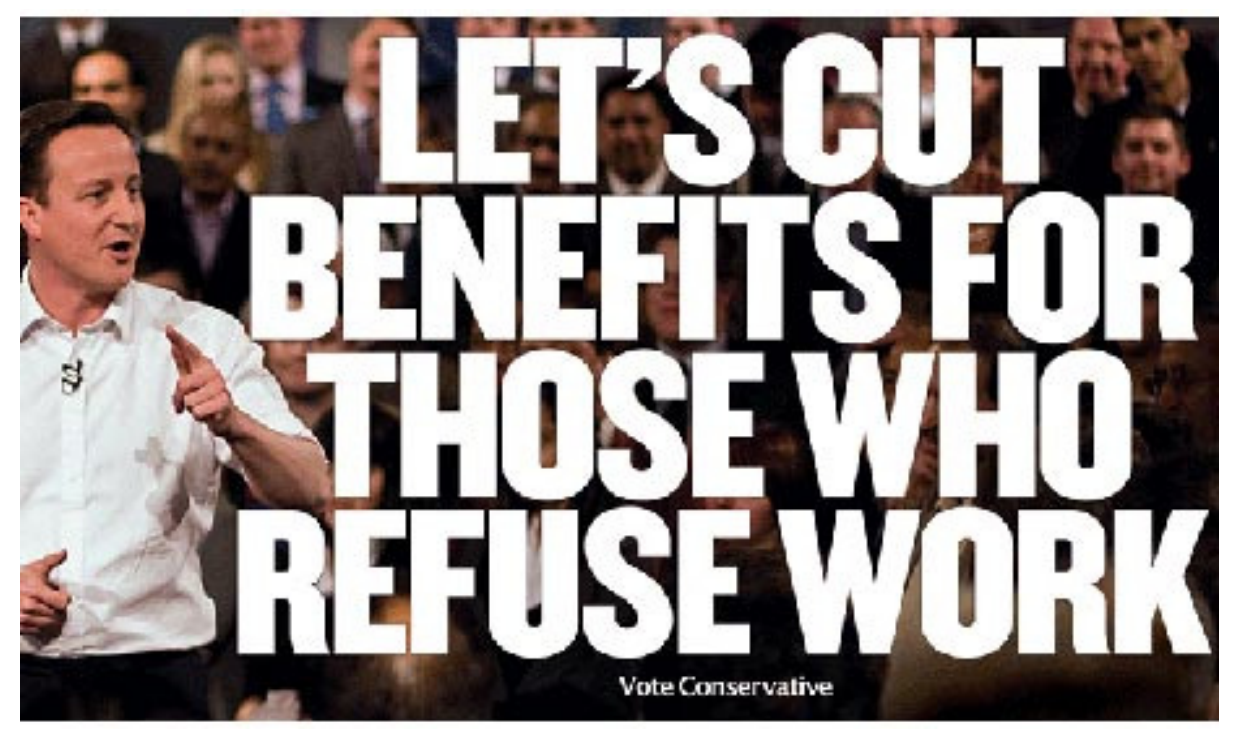

Cameron mostraba un "thatcherismo de rostro humano" (Denham, Garnett and Dorey, 2011, p.157), como un líder atractivo que volvía a situar la economía como un campo de batalla electoral clave, conjugada con la calidad de vida, alguien capaz de frenar el excesivo gasto público y hacer frente al déficit fiscal del país. Sin un gobierno fuerte, advirtieron los conservadores más veteranos, los mercados financieros internacionales no se convencerían de que Gran Bretaña disponía de un liderazgo político lo suficientemente fuerte y decidido como para reducir el déficit y recuperar la credibilidad.

Teniendo en cuenta además la creciente personalización de la política británica, el relajado Cameron, que se mostraba a gusto con el público, presentaba un carácter bien distinto al del irascible y escaso de habilidades sociales, David Brown. No en vano, Cameron, que había sido responsable de asuntos corporativos de la compañía de medios de comunicación Carlton Communications, demostraba un buen manejo de la escena, con una telegenia similar a la demostrada por Blair.

Por lo que respecta a la campaña de Brown, la cantidad de publicidad mostrada por los conservadores supuso una interpretación de doble sentido a la declaración del director de campaña de los laboristas, Douglas Alexander, cuando aseguró que estas elecciones serían ganadas por la gente, no por los 
carteles. Una declaración implícita de esperanza, según algunos, dadas las precarias finanzas del partido de Brown en contraste con la ofensiva publicitaria observada en las anteriores elecciones de 2005 (Alexander, 2010), o una apuesta, según otros, por potenciar los carteles online y la publicidad a través de la red.

Este punto de vista fue promocionado por los asesores y agencia del partido, Saatchi y Saatchi, quienes jugaron con el nombre de su candidato para tratar de convertir su debilidad, su imagen de hombre aburrido y trabajador, en una fortaleza y, a la vez, ponerlo en contraste, indirectamente, con su oponente, al compararlo con un personaje de cómic y ciencia ficción, como fue "Flash Gordon", para decir que este candidato era real y no un simple producto del marketing.

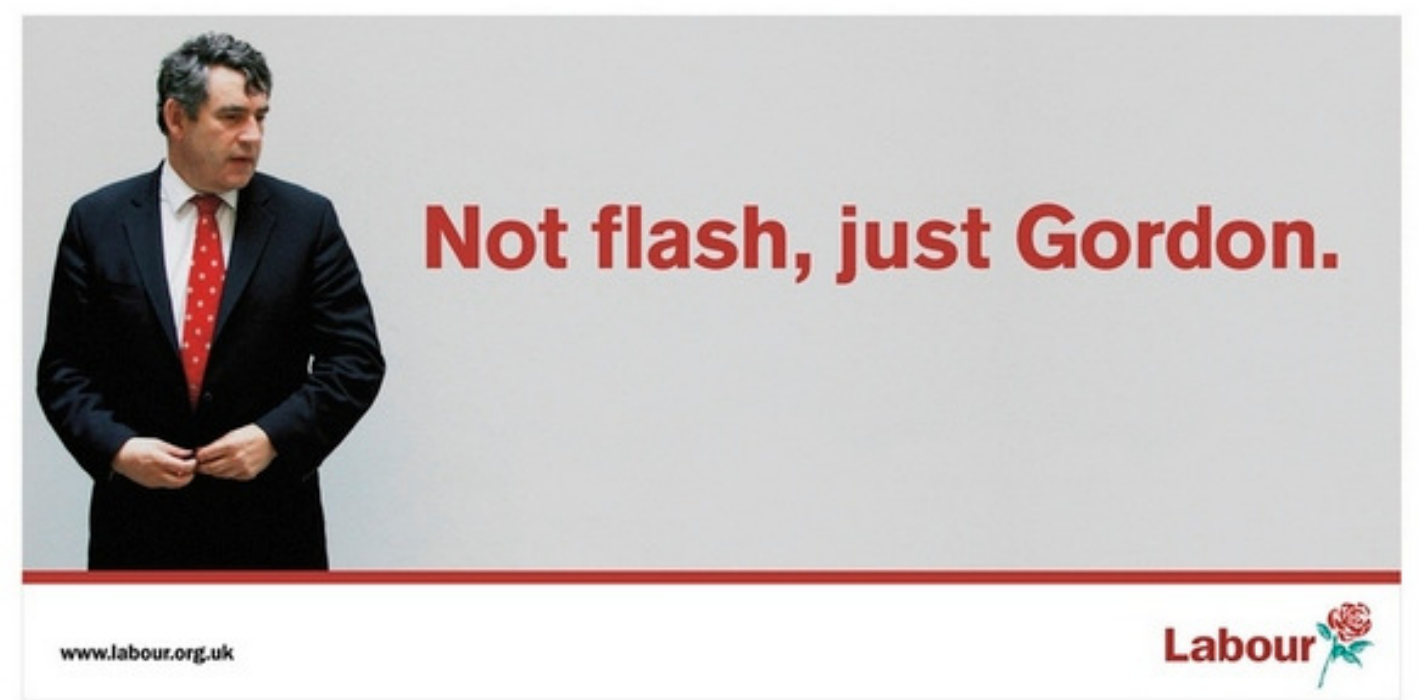

De hecho, en toda estrategia de comunicación de cambio de producto o reposicionamiento, las élites políticas pueden cambiar su producto, cambiar de dirección y decisiones, pero para ganar el apoyo público y lograr cualquier impacto, este cambio debe ser observado, tal y como indica Less-Marshment (2001, p.26). Además, para que ese cambio se perciba como real, tiene que asentarse y pasar cierto tiempo ${ }^{6}$.

El cuidado tratamiento de la imagen de Cameron so observó como un logro político que contribuía a recuperar el orgullo de pertenecer al partido 
conservador. Con tal fin, se aplicaron una serie de técnicas para mostrar que el producto había cambiado, como utilizar un estilo fresco, dinámico y joven (la imagen de David Cameron acudiendo a su trabajo en bicicleta por las calles de Londres era parte de esta comunicación), a través del empleo de formas no convencionales de comunicación que también contribuían a atraer la atención, etiquetando la campaña como moderna y logrando "hacer anuncios que hacen noticia" (Less-Marshment, 2001, p.137).

Un paso más en la búsqueda de la mayor frescura y creatividad para la campaña fue el concurso convocado por Saatchi ganado por un joven de 24 años, asociando la imagen de Cameron a la de un detective de una famosa serie de televisión (Ashes to Ashes, de la BBC) de la época de Margaret Thatcher y pidiendo al electorado, precisamente, que no permitiese que el país regresase a los años 80. Una campaña ágilmente respondida por los conservadores, con el mensaje de "enciende el Quattro" (el Audi utilizado en la serie), porque es tiempo de cambio, acompañada, además, por la coletilla burlona de "idea amablemente donada por el Labour Party".

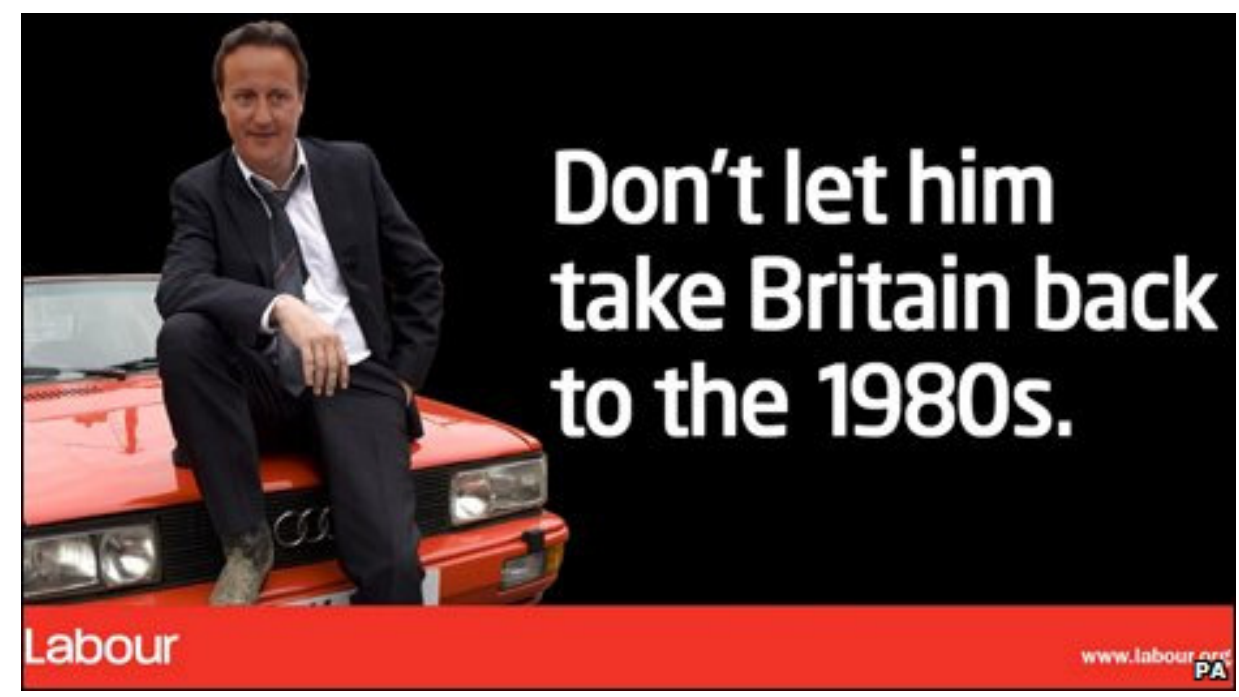




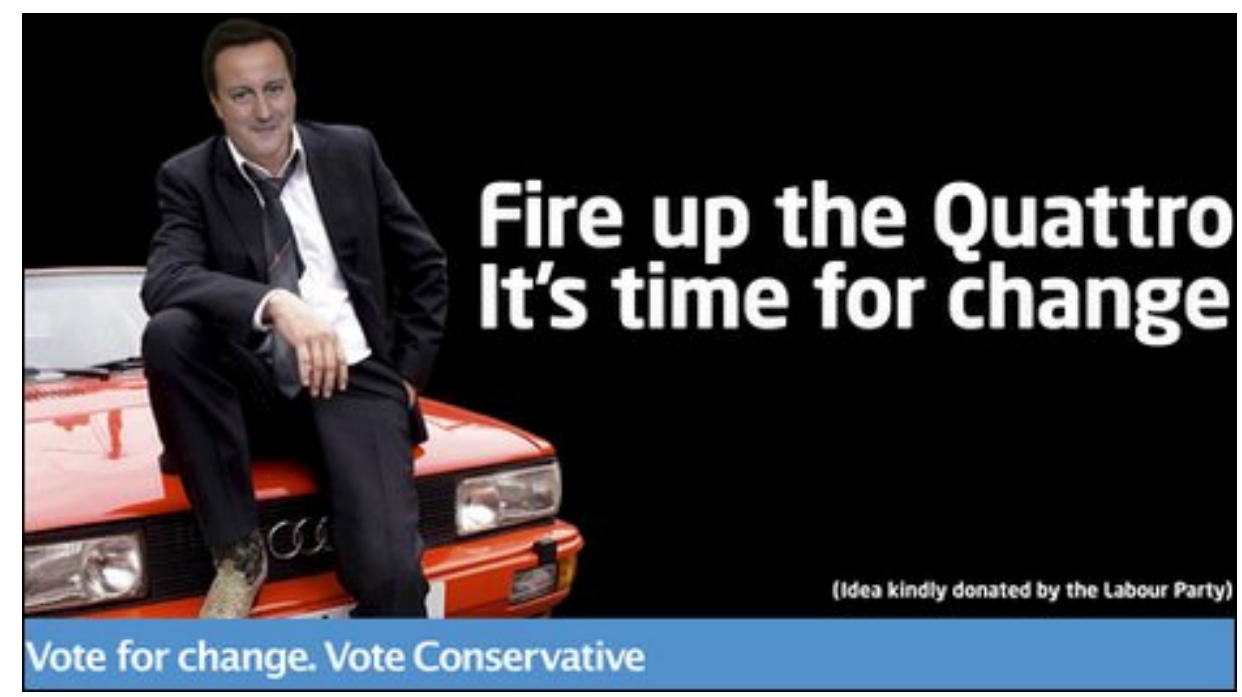

Pero el mayor esfuerzo final por parte de los laboristas fue una campaña en tono positivo en la que un niño recordaba a su madre que no se olvidara de votar al partido, con otras dos piezas, dirigidas al padre y el abuelo, como un llamamiento explícito a los votantes a pensar en el futuro de sus hijos.

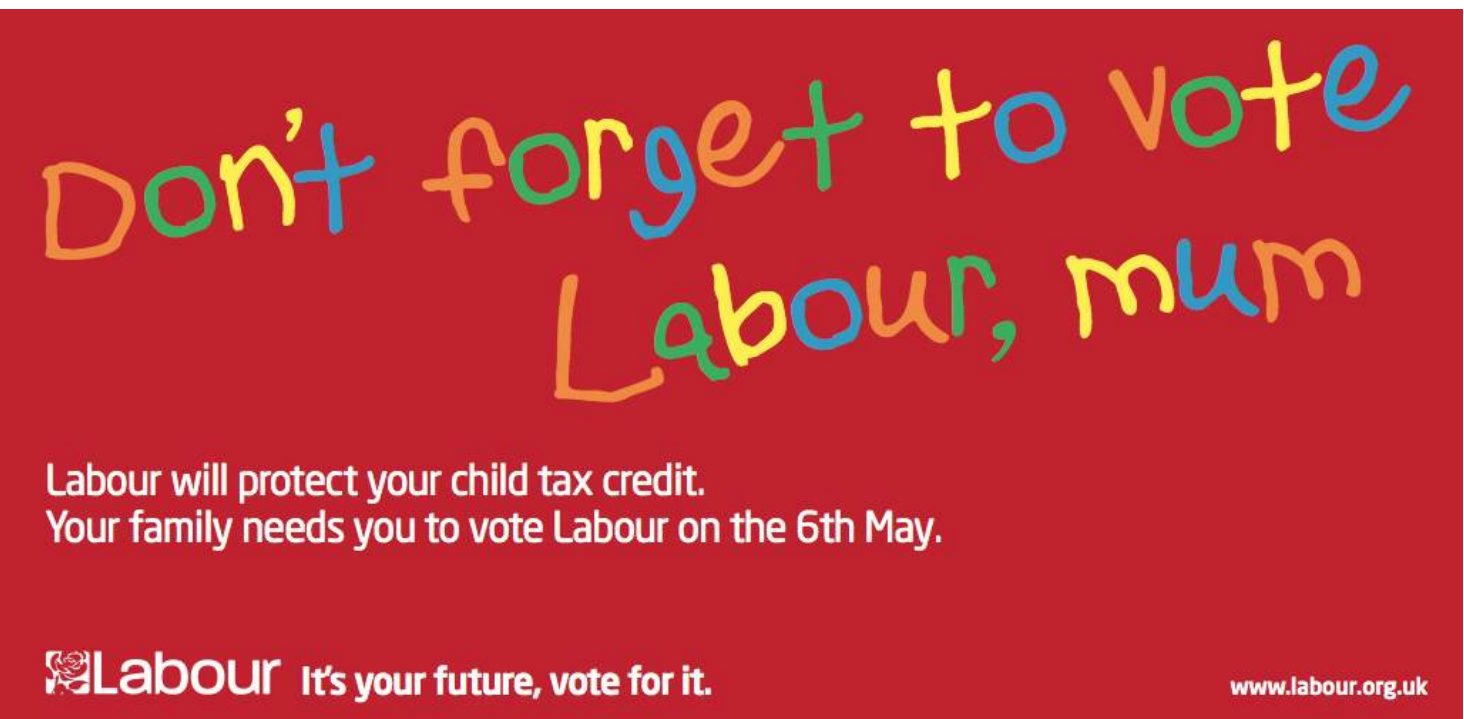

Por su parte, los liberal-demócratas insistirían en posicionarse como tercera marca, alternativa entre los liberales y conservadores, partiendo, precisamente, de la original idea de la agencia Iris de diseñar un logotipo en el que utilizaban 
los recursos de ambas formaciones partidos y su denominación, para crear un nuevo partido, el "Labservative", con un nuevo líder, "Gorvid Camerown", que ofrecía más de lo mismo, incidiendo además en los escándalos, la recesión económica y la guerra fomentados por sus contrincantes. Una publicidad cuyos colores incluso se superponían, en su diseño, sobre el rojo corporativo de los laboristas y el azul de los conservadores.

wwwlabservative.co.nk

\section{SCANDAL. RECESSION. WAR.}

THERE'S NO SUBSTITUTE FOR EXPERIENCE.

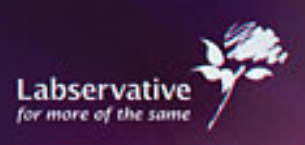

El partido también parodiaría la campaña de la "bomba" lanzada por los Tories para referirse a otra bomba, la de los impuestos, lista para ser lanzada por los conservadores si ganaban las elecciones.

\section{Conclusiones}

Del repaso por las campañas, estrategias y tácticas de comunicación, así como el papel de las agencias, los medios y soportes empleados durante los cuatro últimos procesos electorales generales desarrollados en el Reino Unido, se derivan tres conclusiones básicas del artículo.

La primera, es la gran tradición y profesionalización de la comunicación política existente en el Reino Unido, con ejemplos y datos de antecedentes históricos del empleo de técnicas y herramientas de investigación de mercado, su 
traslación del terreno comercial al electoral y aplicación a la publicidad política. Una tradición observada, igualmente, en la marcada mediatización política existente en el Reino Unido, con el clásico papel desarrollado por los spin doctors, intensificado en los últimos tiempos por la creciente competencia, la incorporación de los escándalos del poder y la utilización -y abuso, como en el reciente caso Murdoch- del poder de los medios, como parte del negocio mediático.

La segunda de las conclusiones es el gran paralelismo y relación existente entre las campañas, candidatos y equipos electorales del Reino Unido y USA (especialmente visible en los casos de Tony Blair y Bill Clinton). Sin entrar en el debate sobre la supuesta americanización de las campañas, presente también en el Reino Unido, lo cierto es que, dentro de esa nueva etapa del periodismo político descrita por algunos autores, centrada en el papel y protagonismo de la comunicación política como tal, se observa la gran personalización y focalización en la imagen y atributos de los líderes durante las últimas campañas, además de la deriva hacia la denominada "Talk-Show Democracy" televisiva y el creciente predominio de la publicidad negativa.

Campañas y contracampañas producidas con gran ingenio y creatividad que generan un fuerte impacto y capacidad de respuesta, lo cual lleva a la tercera y última de las conclusiones o, cuando menos, reflexión abierta: si esta publicidad y contrapublicidad (visible no sólo como "alternativa" a través de la red, sino también incorporada, formalmente, a los canales y soportes tradicionales), representa una tendencia para el resto de los países del entorno.

\section{BIBLIOGRAFÍA}

Alexander, D. (2010) "This election will be won by people, not posters": The Douglas Alexander interview' (internet), http://labourlist.org/2010/03/thiselection-will-be-won-by-people-not-posters-the-douglas-alexanderinterview/. Recuperado el 28 de marzo de 2012. 
Blair, Tony (2003): "Blair's conference speech", The Guardian: https://www.theguardian.com/uk

Recuperado el 30 de marzo de 2011.

Blumler, Jay; Gurevitch, Michael (2001). "Americanization. Reconsidered: U.K.U.S. Campaign Communication Comparisons Across Time”. En: Bennet and Entman (eds.). Mediated Politics. Cambridge: Cambridge University Press.

Bower, T. (2005). Gordon Brown. London: HarperCollins.

Brants, Kees; Voltmer, Katrin (2011). Political Communication in Postmodern Democracy. Challenging the primacy of Politics. London: Palgrave MacMillan.

Butler, David; Kavanagh, Dennis (1992). The British General Election of 1992. London: Palgrave.

Campbell, A. (2007). The Blair Years. London: Hutchinson.

Castle, Stephen (1998). "We only speak if wue fell like it". En: Independent on Sunday, 5 de Julio de 1998.

Cook, Greg (2011). "The Labour Party's Road to 2010". En: Wring, D; Mortimore, R. Atkinson, S. (Eds.). Political Communication in Britain. The Leader Debates, The Campaign and the Media in the 2010 General Election. London: Palgrave MacMillan.

Cowley, Ph. and Green, J. (2005). "New leaders, same problems: The Conservatives". En: Geddes, Andrew and Tonge, Jonathan (eds.). Britain decides. The UK General Election 2005. London: Palgrave Macmillan.

Denham, A.; Garnett, M; Dorey, P. (2011). From Crisis to Coalition. The Conservative Party, 1997-2010. London: Palgrave Macmillan.

Downs, A. (1957). An Economic Theory of Democracy. New York: Harper \& Row.

Fieldind, Steven (2005). "Neither forward nor back". En: Geddes, Andrew and Tonge, Jonathan (eds.). Britain decides. The UK General Election 2005. London: Palgrave Macmillan.

Fielding, Steven. (2003). The Labour Party. Continuity and Change in the Making of "New" Labour, Basingstoke: Palgrave. 
Finkelstein, Daniel (1998). "Why Conservatives Lost". En: Crewe, Ivor; Gosschalk, Brian; Bartle, John (edits.). Why Labour won the General election of 1997. London: Frank Cass Publishers.

Foley, Michael (2000). The British Presidency. London and New York: Manchester University Press.

Gandy, O. H. (1982). Beyond Agenda Setting: Information Subsidies and Public Policy. Norwood: Ablex.

Gould, Philip (1998). "Why Labour Won". En: Crewe, Ivor; Gosschalk, Brian; Bartle, John (edits.). Why Labour won the General election of 1997. London: Frank Cass Publishers.

Gould, Philip (1998). The Unfinished Revolution: How the Modernisers Saved the Labour Party. London: Little Brown.

Hallin, D. C.; Mancini (2004). Comparing Media Systems: Three Models of Media and Politics. Cambridge: Cambridge University Press.

Hills and Stewart (2005) A More Equal Society?. New Labour, Poverty, Inequality and Exclusion. London: Policy Press.

Holme, Ricard and Alison (1998). "Sausages or Policeman. The role of the Liberal Democrats in the 1997 General election Campaign. En: Crewe, Ivor; Gosschalk, Brian; Bartle, John (edits.). Why Labour won the General election of 1997. London: Frank Cass Publishers.

Hoskin, P. (2010) 'A poster that cuts to the chase' (internet), Spectator, posted 20 April, http://www.spectator.co.uk/coffeehouse/5928608/a- poster- thatcutsto- the- chase.thtml. Recuperado el 27 de marzo de 2012.

Ingham, B. (2003). He Wages of Spin. London: John Murray.

Ingham, B. (1991). Kill the Messenger. London: HarperCollins.

Kavanagh, D. and Cowley, P. (2010). The British General Election of 2010. Basingstoke: Palgrave MacMillan.

Kavanagh, Dennis (1995). Election Campaigning: The New Marketing of Politics. Oxford: Blackwell.

Langer, Ana (2010). "The Politization of Private Persona: Exceptional Leaders or the New Rule?. The Case of the United Kingdom and the Blair Effect". International Journal of Press/Politics, №15 (1), pp. 60-76. London: Sage Publications. 
Less-Marshment, Jennifer (2011). The Political Marketing Game. London: Palgrave MacMillan.

McNair, Brian (2011). An Introduction to Political Communication. London and New York: Routledge.

McSmith, A. and Morris, N. (2010) 'Web satires trigger Tory ads rethink' (internet), Independent, posted 15 February 2010, http://www.independent.co.uk/news/uk/politics/web- satires- trigger- toryads- rethink- 1899541.html . Recuperado el 28 de marzo de 2012.

Milburn, A. (2004). www.ippr.org.uk/articles and 2005: www.fabiansociety.org.uk/press_office. Recuperado el 30 de abril de 2012.

Morris, Dick; Rosales, Luis (2007). El poder. Argentina: Editorial Sudamericana.

Price, Lance (2010). Where Power Lies. Prime Ministers vs. the Media. London and New York: CBS Company.

Richardson, M. (2010) 'Tories' Latest Campaign Poster' (internet), Sky News $\begin{array}{llll}\text { Blog, } & 9 & \text { February }\end{array}$ http://blogs.news.sky.com/boultonandco/Post:a935dcf5- 4cc7- 4e3b8a32- d2bdc268911a. Recuperado el 25 de marzo de 2012.

Scammell, Margaret (1995). Designer Politics: How Elections are Won. Basingstoke: Macmillan.

Scott, Derek (2004). Off Whitehall. A view from Downing Street by Tony Blair's Adviser. London: Tauris \& Co Ltd.

Tumber, Howard (2004). Scandal and Media in the United Kindom. From Major to Blair. American Behavioral Scientist, Vol. 7, no8.

Wayne, Mike; Murray, Craig (2009). U.K. Television News: Monopoly Politics and Cynical Populism. Television \& New Media, Sage Publications, vol.10, n5, septiembre.

Wilson, Alex (2011). "The Conservative Campaign". En: Wring, D; Mortimore, R. Atkinson, S. (Eds.). Political Communication in Britain. The Leader Debates, The Campaign and the Media in the 2010 General Election. London: Palgrave MacMillan.

Wring, Dominic (1996). "From Mass Propaganda to Political Marketing: The transformation of Labour Party Election Campaigning". En: Colin Rallings 
et al. (eds). British Parties and Elections Yearbook, 1995. London: Frank Cass.

\begin{abstract}
NOTAS
${ }^{1}$ La tradicional oposición de la mayor parte de los dueños y editores de la prensa inglesa a la entrada del país en la Unión Europea y la moneda única, se observó como un ejemplo del poder de influencia de los medios sobre la opinión pública y una muestra de la defensa de los intereses corporativos de los grandes empresarios de la comunicación, en su afán proteccionista.

${ }^{2}$ El propio Tony Blair, como líder de la oposición, viajaría al domicilio de Murdoch en Australia, en julio de 1995, para pronunciar una conferencia en el círculo de confianza del magnate de la comunicación, lo cual se entendió como el inicio del cortejo del laborista con el empresario.

${ }^{3}$ Según el propio Morris, "cuando una situación política se encuentra empantanada sin que se atisbe una solución, trabada entre dos bandos que no logran superarse, suele ser conveniente encontrar una tercera vía que incorpore propuestas de ambos lados del péndulo" (Morris y Rosales, 2007, p.193).

${ }^{4}$ http://www.youtube.com/watch?v= kbaXYPmjU0 . Recuperado el 25 de marzo de 2011.

5 http://ivenevervotedtory.wordpress.com/ . Recuperado el 27 de marzo de 2012.

6 Precisamente, el tiempo sería testigo de las críticas realizadas a Cameron, recientemente, por sus "torpezas políticas" y "deslices" que "le convierten en el hazmerreír del Reino Unido", así como el "elitismo de un gabinete dominado por gente que no vive en el mundo real, que no conecta con los problemas cotidianos del ciudadano medio porque no sabe como vive". Un primer ministro sobre el que The Sunday Times revelaba, en su edición del 25 de marzo de 2012, el fácil acceso de una casta de privilegiados donantes a la residencia de Cameron en Downing Street. Cfr. El País, 1 de abril de 2012, p.5.
\end{abstract}

Para citar este artículo:

Rúas Araújo, José (20-06-2012). CAMPAÑAS ELECTORALES Y PUBLICIDAD POLÍTICA EN EL REINO UNIDO.

REDMARKA - CIECID - Unidad de Investigación en Marketing Aplicado-Universidad de A Coruña

Año V, Número 8, V1, pp.3-39

ISSN 1852-2300

URL del Documento : cienciared.com.ar/ra/doc.php? $n=1653$

URL de la Revista : cienciared.com.ar/ra/revista.php? wid=39 